\title{
A Maieutic Exploration of Nudging Strategies for Regional Climate Applications Using the WRF Model
}

\author{
Tanya L. Spero, Christopher G. Nolte, and Megan S. Mallard \\ National Exposure Research Laboratory, U.S. Environmental Protection Agency, Research Triangle Park, North Carolina \\ JARED H. BOWDEN \\ Department of Applied Ecology, North Carolina State University, Raleigh, North Carolina
}

(Manuscript received 22 December 2017, in final form 9 April 2018)

\begin{abstract}
The use of nudging in the Weather Research and Forecasting (WRF) Model to constrain regional climate downscaling simulations is gaining in popularity because it can reduce error and improve consistency with the driving data. While some attention has been paid to whether nudging is beneficial for downscaling, very little research has been performed to determine best practices. In fact, many published papers use the default nudging configuration (which was designed for numerical weather prediction), follow practices used by colleagues, or adapt methods developed for other regional climate models. Here, a suite of 45 three-year simulations is conducted with WRF over the continental United States to systematically and comprehensively examine a variety of nudging strategies. The simulations here use a longer test period than did previously published works to better evaluate the robustness of each strategy through all four seasons, through multiple years, and across nine regions of the United States. The analysis focuses on the evaluation of 2-m temperature and precipitation, which are two of the most commonly required downscaled output fields for air quality, health, and ecosystems applications. Several specific recommendations are provided to effectively use nudging in WRF for regional climate applications. In particular, spectral nudging is preferred over analysis nudging. Spectral nudging performs best in WRF when it is used toward wind above the planetary boundary layer (through the stratosphere) and temperature and moisture only within the free troposphere. Furthermore, the nudging toward moisture is very sensitive to the nudging coefficient, and the default nudging coefficient in WRF is too high to be used effectively for moisture.
\end{abstract}

\section{Introduction}

Newtonian relaxation (commonly called nudging) can be used within Eulerian models to gently force the solution toward a physical reference state. This forcing occurs through an additional term in the prognostic equations that is based on the difference between the model's realization of a prognostic field and the corresponding reference state. The reference state is observation based when nudging is used either for forecast initialization or to create dynamical analyses of historical conditions; for regional climate modeling, the reference state originates from a global climate model's coarse realization of the atmosphere. The nudging terms can also be scaled to account for the accuracy and representativeness of the reference state at the modeled

\footnotetext{
Corresponding author: T. L. Spero, spero.tanya@epa.gov
}

location, in addition to the time scale of the phenomena that are simulated.

Nudging began in limited-area NWP [expansions of the acronyms used in this paper can be found online (https://www.ametsoc.org/PubsAcronymList)] as a "dynamic initialization" technique to improve initial conditions by applying nudging continuously during a short preforecast period (Anthes 1974; Hoke and Anthes 1976). Using nudging throughout a meteorological simulation to form a "dynamic analysis" was introduced by Stauffer and Seaman (1990), and continuously nudged meteorological fields typically serve as input for retrospective Eulerian air-quality modeling (e.g., Stauffer et al. 1993; Tanrikulu et al. 2000; Otte 2008). Nudging was adapted and applied for regional climate modeling by von Storch et al. (2000), who recognized the value of retaining large-scale information within the domain interior while dynamically downscaling global climate data, and they extended the 
spectral technique of Waldron et al. (1996) for that purpose.

Dynamical downscaling uses a physics-based regional climate model to project regional and local-scale climate features at finer spatial and temporal resolutions than are available from global models (e.g., Dickinson et al. 1989; Giorgi 1990; Feser et al. 2011). Although the WRF Model (Skamarock and Klemp 2008) was not specifically developed for regional climate modeling, it has become ubiquitous for dynamical downscaling. WRF has been used to examine regional climate in historical simulations forced by reanalysis fields to test and evaluate the efficacy of the downscaling procedure as well as to examine future climate change and its implications on air quality (e.g., Trail et al. 2013; Gonzalez-Abraham et al. 2015; Seltzer et al. 2016), human health (e.g., Fann et al. 2015; Wilson et al. 2017), and water quality and quantity (e.g., ArnbjergNielsen et al. 2013; Nover et al. 2016).

Two types of nudging in the WRF Model have been used in dynamical downscaling: analysis nudging and spectral nudging. The analysis nudging in WRF (Deng et al. 2007) follows its implementations in MM4 and MM5 (Stauffer and Seaman 1990, 1994; Stauffer et al. 1991). Analysis nudging relaxes the model toward the difference between the simulated fields and the spatial and temporal interpolations of the reference state at each grid point. Analysis nudging in WRF can be performed on horizontal wind components, potential temperature, and water vapor mixing ratio (i.e., moisture). Although analysis nudging was originally designed to incorporate high-resolution observational datasets, using analysis nudging toward coarse-scale global fields can improve the skill of regional climate simulations with WRF when compared with not nudging the interior of the domain (e.g., Lo et al. 2008; Bowden et al. 2012, 2013; Otte et al. 2012; Omrani et al. 2013, 2015; Bullock et al. 2014; Wootten et al. 2016).

Spectral nudging in WRF follows the implementation in RAMS (Miguez-Macho et al. 2004, 2005). Similar to von Storch et al. (2000), spectral nudging in WRF involves a Fourier decomposition of the difference between modeled and reference states, and the longest waves in the WRF simulation are then relaxed toward the equivalent wavelengths in the reference state. Spectral nudging is theoretically more attractive than analysis nudging for regional climate modeling because nudging can be restricted to the resolvable features in the driving (i.e., reference) data, which are typically coarser for climate downscaling than for NWP. Spectral nudging in WRF can be performed on horizontal wind components, potential temperature, and geopotential, as well as on moisture with an extension from Spero et al. (2014). Spectral nudging has also been shown to improve dynamically downscaled WRF simulations relative to not nudging at all (e.g., Liu et al. 2012; Bowden et al. 2012, 2013; Otte et al. 2012; Omrani et al. 2012; Glisan et al. 2013; Spero et al. 2014). Spectral nudging is also available in several other regional climate models.

Although nudging is not universally accepted in dynamical downscaling (e.g., Flato et al. 2013), it improves the skill of simulations driven by historical (i.e., verifiable) data across various regional climate models, and we have found that nudging makes a greater impact on the simulations than exchanging physics options. Both Denis et al. (2002) with CRCM and Miguez-Macho et al. (2004) with RAMS applied spectral nudging to eliminate the effect of domain size on the regional climate solution by controlling internal variability. Lo et al. (2008) showed that analysis nudging in WRF substantially improves downscaled simulations throughout the troposphere. Feser et al. (2011) reviewed several studies that applied spectral nudging and illustrated that those simulations consistently added value over the coarser driving simulations. Otte et al. (2012) showed that nudging improves WRF's simulation of means, variability, and extremes. Bowden et al. (2013) demonstrated that nudging improves regional atmospheric circulation anomalies in WRF. Scinocca et al. (2016) used CanESM2 to show that spectral nudging in the driving model also improves the downscaled simulation in the nested CRCM.

Although various nudging strategies (i.e., suites of variables, associated nudging coefficients, and layers where nudging is applied) have been shown to improve regional climate simulations with WRF, there has been little research to determine how to use it most effectively. Furthermore, nudging strategies developed in other regional climate models may not translate to WRF because of differences in prognostic variables, implementations, or vertical coordinate systems. Several studies examined nudging strategies in WRF to simulate regional climate in midlatitudes (e.g., Lo et al. 2008; Bowden et al. 2012; Liu et al. 2012; Omrani et al. 2012, 2013; Bullock et al. 2014), and these studies focused on simulations up to a 1-yr period. Glisan et al. (2013) examined spectral nudging for Arctic simulations, and Pohl and Crétat (2013) and Wootten et al. (2016) explored how to use nudging for regional climate modeling in the tropics and subtropics. Spero et al. (2014) conducted multiple sensitivity simulations of spectral nudging toward water vapor mixing ratio to improve the clouds, radiation, and precipitation. Omrani et al. (2015) performed 11 idealized "big brother" sensitivity simulations (e.g., Denis et al. 2002) for 3-month simulations in summer and winter to determine the effects of nudging various parameters in WRF; they used constant 
nudging time scales for all variables, however, and the simulations did not include the full annual cycle. Omrani et al. (2015) applied the nudging coefficient from Omrani et al. (2013) to all nudged variables, but they suggested that the optimal nudging coefficients may be related to the WRF configuration. Furthermore, it may be inappropriate to unify the nudging coefficients for all variables (e.g., Stauffer and Seaman 1994; Otte 2008; Otte et al.2012). Although nudging coefficients could be dynamically optimized using variational and adjoint modeling (Zou et al. 1992; Stauffer and Bao 1993), this has not been operationalized in NWP and is impractical for dynamical downscaling because of the computational demands of such an approach.

Here, 45 nudging strategies are evaluated using continuous 3-yr simulations to elucidate both good and bad practices and to identify appropriate nudging strategies for midlatitude regional climate simulations with WRF. These simulations are not an ensemble; rather, they are designed to explore functionalities in nudging with WRF for regional climate modeling. The evaluation focuses on 2-m temperature and precipitation, two of the most commonly used fields in studies of air quality, health, and ecosystems impacts that rely on future regional climate projections. The nudging strategies here are built upon published practices derived from modeling applications driven by high-resolution observational data, published nudging studies over shorter periods, and nudging strategies applied in other regional climate models. In addition, some of the simulations are chosen with aspects of their nudging strategies intentionally exaggerated to demonstrate the importance of using nudging appropriately. Section 2 describes the experiment design and WRF modeling configuration used here. Section 3 includes the analysis of the full suite of simulations to assess how model performance varies across the suite and what groups of simulations are most skillful. Section 4 examines themes that emerge among the nudging simulations. Section 5 is a further analysis of the most skillful simulations. The final section offers recommendations for the dynamical downscaling community.

\section{Experiment design}

\section{a. WRF Model configuration}

Dynamical downscaling simulations using WRF, version 3.2.1, were initialized at 0000 UTC 2 December 1987 following Otte et al. (2012) and were run continuously for 37 months to perform the analysis for 1988-90. Two-waynested domains with 108 - and $36-\mathrm{km}$ horizontal grid spacing covered North America and the contiguous United States (CONUS), respectively, using a 34-layer configuration to a model top at $50 \mathrm{hPa}$; analysis is conducted on the 36-km domain (Fig. 1). The initial, lateral, and surface boundary conditions and the constraints for interior nudging are derived from $6-\mathrm{h}, 2.5^{\circ} \times$ $2.5^{\circ}$ reanalyses from R-2 (Kanamitsu et al. 2002). The WRF modeling configuration and physics options follow Otte et al. (2012), including the RRTM for global climate models (Iacono et al. 2008) for longwave and shortwave radiation, the WRF single-moment six-class microphysics scheme (Hong and Lim 2006), the Grell ensemble convective parameterization scheme (Grell and Dévényi 2002), the Yonsei University planetary boundary layer (PBL) scheme (Hong et al. 2006), and the Noah land surface model (Chen and Dudhia 2001).

\section{b. Nudging simulations}

There are 45 three-year simulations: 1 without nudging, 19 with analysis nudging, and 25 with spectral nudging (Table 1 ). These simulations examine sensitivities to the type of nudging that is used, nudging coefficients, fields that are nudged, and the portion of the atmospheric column to which nudging is applied. The nudging reference fields are spatial interpolations of R-2 to the WRF domains; no additional observational data are incorporated in the driving fields. In the spectralnudging simulations, the $X$ and $Y$ wavenumbers are set to 5 and 3 , respectively, on the $108-\mathrm{km}$ domain and to 4 and 2 , respectively, on the $36-\mathrm{km}$ domain; those wavenumbers constrain the simulations toward the resolvable waves in R-2 as a function of the spatial extent of each domain (Fig. 1).

The default nudging coefficients in WRF are $3.0 \times$ $10^{-4} \mathrm{~s}^{-1}$ for each variable. That value was inherited from observation-driven studies conducted using analysis nudging in WRF's predecessors, MM4 and MM5 (Stauffer and Seaman 1990, 1994; Stauffer et al. 1991). The nudging coefficients are reciprocal time scales of the physical processes in the data toward which the model is nudged.

The first three simulations are from Otte et al. (2012): no nudging $(\mathrm{NN})$, a simulation with analysis nudging (AN), and a simulation with spectral nudging (SN). Simulation AN used default nudging coefficients for wind and temperature on the outer domain and a lower nudging coefficient both for moisture (Stauffer and Seaman 1994) and on the nested domain (Stauffer and Seaman 1994). Simulation SN used default nudging coefficients to nudge wind, potential temperature, and geopotential on both domains. The remaining sensitivity simulations are based on systematic changes to AN and SN from Otte et al. (2012). Many of the simulations include sensitivities of nudging different subsets of the atmospheric column, as well as isolating nudging toward different variables. Spectral nudging toward moisture 


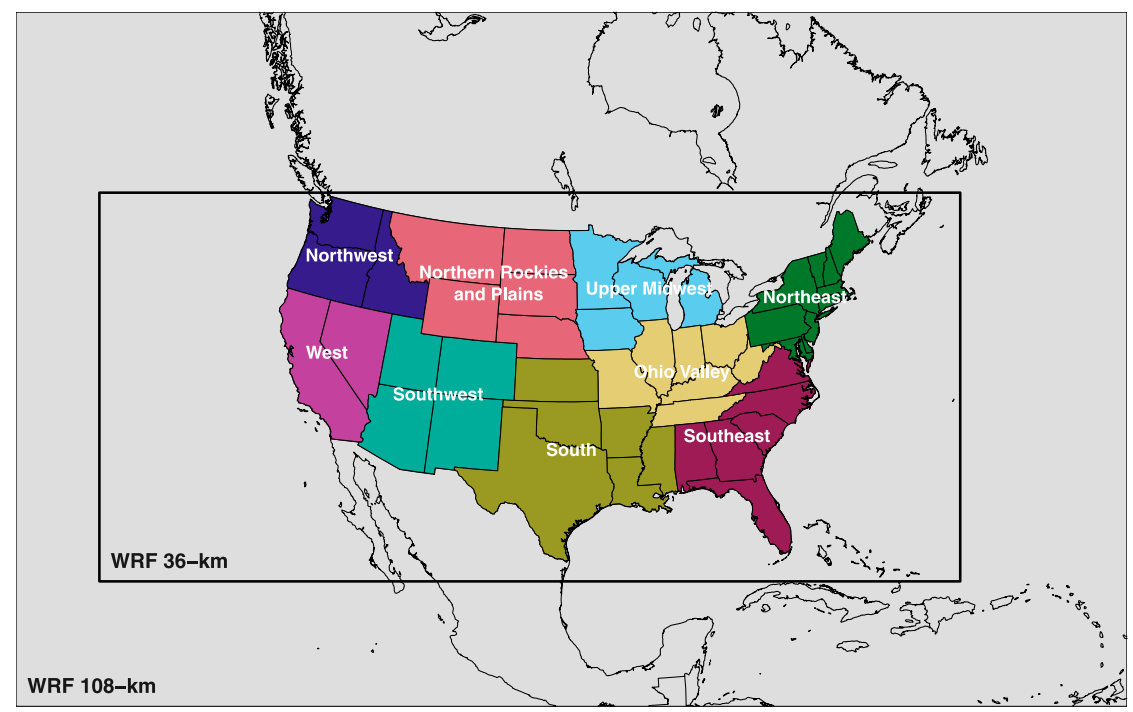

FIG. 1. WRF domains and NCEI U.S. climate regions.

(simulations 29-34 and 36-41 in Table 1) uses the implementation from Spero et al. (2014), which was made available in WRF, version 4.0.

\section{Examining the full suite of simulations}

\section{a. Datasets for validation}

Analysis of the 2-m temperature and precipitation is conducted within the nine U.S. climate regions defined by Karl and Koss (1984) and used by the National Centers for Environmental Information (NCEI; Fig. 1). These regions were established for the CONUS on the basis of historical climatic information and following state boundaries. Analysis is conducted for 2-m temperature (mean, daily maximum, and daily minimum) and accumulated monthly and daily precipitation, as well as five indices of climate extremes. Temperature extremes are examined with frost days (minimum 2-m temperature $<0^{\circ} \mathrm{C}$ ), summer days (maximum 2-m temperature $>25^{\circ} \mathrm{C}$ ), icing days (maximum 2-m temperature $<0^{\circ} \mathrm{C}$ ), and tropical nights (minimum 2 -m temperature $>20^{\circ} \mathrm{C}$ ). These extreme temperature indices are among those promoted by NCEI North American Climate Extremes Monitoring and ETCCDI to objectively characterize climate variability and change. Extreme precipitation is evaluated using a daily 0.5 -in. $(1$ in. $=2.54 \mathrm{~cm})$ accumulation threshold tracked by NCEI.

The data that are used for validation are independent of the driving data (R-2) and were not used for nudging. Each validation dataset is interpolated to the WRF 36-km domain to facilitate direct comparisons at land points. The $36-\mathrm{km}$ WRF simulations of hourly $2-\mathrm{m}$ temperature are compared with the hourly $0.31^{\circ}$ CFSR
(Saha et al. 2010). The 3-h, 32-km NARR 2-m temperature (Mesinger et al. 2006) was corroborated with CFSR and found to be broadly consistent (cf. Otte et al. 2012). Validation of precipitation is conducted using the NOAA CPC $0.25^{\circ}$ analysis and against NARR. Precipitation from CPC and NARR were compared, and they are qualitatively similar (not shown); the analysis focuses only on validations of precipitation against CPC. Simulated precipitable water is compared with NARR.

\section{b. Relative ranked RMSE across the regions}

Analysis is performed for 1988-90. RMSE in mean 2-m temperature and daily maximum 2-m temperature are compared with CFSR, and precipitation is compared with CPC (Figs. 2-4). The daily minimum 2-m temperature is qualitatively similar to mean 2-m temperature but with higher RMSE (not shown). The overall skill of each nudging strategy in any particular region (relative to the other strategies evaluated) is consistent regardless of whether RMSE or MAE is used (not shown); RMSE is selected following Chai and Draxler (2014). In addition, RMSE accentuates the most profound errors, which is important for simulating acute extreme events.

In Figs. 2-4, RMSE is calculated from the 36 monthly values at each cell and then aggregated within the U.S. climate regions (Fig. 1). The CONUS-wide value is area weighted by the number of cells in each region. Because there are large regional differences in the magnitudes of RMSE and in an effort to identify broad trends in model performance, color coding within each region in Figs. 2-4 represents the ordinal rank of each simulation to indicate whether a nudging strategy is consistently more or less skillful than the others across the domain. 
TABLE 1. Nudging specifications for each simulation. The type of nudging used in WRF [analysis (AN) or spectral (SN)] is indicated by the first two letters of each simulation name. In addition, $G_{\alpha}$ are the nudging coefficients $\left(10^{-4} \mathrm{~s}^{-1}\right)$, where $\alpha$ is the nudged field and is set to $U, V$ for horizontal wind components, $T$ for potential temperature, $Q$ for water vapor mixing ratio, and $\Phi$ for geopotential. Nudging is used in all layers above the PBL except when indicated in the "layers" column; layers 17, 21, and 25 represent approximately 800, 700, and $500 \mathrm{hPa}$, respectively. "Mid" in the layers column indicates nudging between the top of the PBL and layer 28 (nominally the tropopause), and either $Q$ or both $Q$ and $T$ are limited to below the tropopause (as indicated by the run name).

\begin{tabular}{|c|c|c|c|c|c|c|c|c|c|c|c|}
\hline \multirow[b]{2}{*}{ Run } & \multirow[b]{2}{*}{ Name } & \multicolumn{5}{|c|}{ 108-km domain } & \multicolumn{5}{|c|}{ 36-km domain } \\
\hline & & $G_{U, V}$ & $G_{T}$ & $G_{Q}$ & $G_{\Phi}$ & Layers & $G_{U, V}$ & $G_{T}$ & $G_{Q}$ & $G_{\Phi}$ & Layers \\
\hline $\mathrm{NN}$ & $\mathrm{NN}$ & 0.0 & 0.0 & 0.0 & 0.0 & & 0.0 & 0.0 & 0.0 & 0.0 & \\
\hline $\mathrm{AN}$ & $\mathrm{AN}$ & 3.0 & 3.0 & 0.45 & & & 1.0 & 1.0 & 0.1 & & \\
\hline $\mathrm{SN}$ & $\mathrm{SN}$ & 3.0 & 3.0 & & 3.0 & & 3.0 & 3.0 & & 3.0 & \\
\hline 01 & ANlow & 1.0 & 1.0 & 0.15 & & & 0.3 & 0.3 & 0.055 & & \\
\hline 02 & SNlow & 1.0 & 1.0 & & 1.0 & & 1.0 & 1.0 & & 1.0 & \\
\hline 03 & ANlow10 & 0.1 & 0.1 & 0.055 & & & 0.03 & 0.03 & 0.01 & & \\
\hline 04 & SNlow10 & 0.1 & 0.1 & & 0.1 & & 0.1 & 0.1 & & 0.1 & \\
\hline 05 & SNphi & 0.0 & 0.0 & & 3.0 & & 0.0 & 0.0 & & 3.0 & \\
\hline 06 & SNtheta & 0.0 & 3.0 & & 0.0 & & 0.0 & 3.0 & & 0.0 & \\
\hline 07 & SNuv & 3.0 & 0.0 & & 0.0 & & 3.0 & 0.0 & & 0.0 & \\
\hline 08 & SNuv25 & 3.0 & 0.0 & & 0.0 & $>25$ & 3.0 & 0.0 & & 0.0 & $>25$ \\
\hline 09 & SN25 & 3.0 & 3.0 & & 3.0 & $>25$ & 3.0 & 3.0 & & 3.0 & $>25$ \\
\hline 10 & SN21 & 3.0 & 3.0 & & 3.0 & $>21$ & 3.0 & 3.0 & & 3.0 & $>21$ \\
\hline 11 & SN17 & 3.0 & 3.0 & & 3.0 & $>17$ & 3.0 & 3.0 & & 3.0 & $>17$ \\
\hline 12 & ANnoq & 3.0 & 3.0 & 0.0 & & & 1.0 & 1.0 & 0.0 & & \\
\hline 13 & ANtheta & 0.0 & 3.0 & 0.0 & & & 0.0 & 1.0 & 0.0 & & \\
\hline 14 & ANuv & 3.0 & 0.0 & 0.0 & & & 1.0 & 0.0 & 0.0 & & \\
\hline 15 & $\mathrm{ANq}$ & 0.0 & 0.0 & 0.45 & & & 0.0 & 0.0 & 0.1 & & \\
\hline 16 & AN25 & 3.0 & 3.0 & 0.45 & & $>25$ & 1.0 & 1.0 & 0.1 & & $>25$ \\
\hline 17 & AN21 & 3.0 & 3.0 & 0.45 & & $>21$ & 1.0 & 1.0 & 0.1 & & $>21$ \\
\hline 18 & AN17 & 3.0 & 3.0 & 0.45 & & $>17$ & 1.0 & 1.0 & 0.1 & & $>17$ \\
\hline 19 & ANlow25 & 1.0 & 1.0 & 0.15 & & $>25$ & 0.3 & 0.3 & 0.055 & & $>25$ \\
\hline 20 & ANlow21 & 1.0 & 1.0 & 0.15 & & $>21$ & 0.3 & 0.3 & 0.055 & & $>21$ \\
\hline 21 & ANlow17 & 1.0 & 1.0 & 0.15 & & $>17$ & 0.3 & 0.3 & 0.055 & & $>17$ \\
\hline 22 & ANuv25 & 3.0 & 0.0 & 0.0 & & $>25$ & 1.0 & 0.0 & 0.0 & & $>25$ \\
\hline 23 & ANhi & 5.6 & 5.6 & 1.0 & & & 1.8 & 1.8 & 0.18 & & \\
\hline 24 & SNhi & 5.6 & 5.6 & & 5.6 & & 5.6 & 5.6 & & 5.6 & \\
\hline 25 & ANpbl & 3.0 & 3.0 & 0.45 & & All & 1.0 & 1.0 & 0.1 & & All \\
\hline 26 & SNpbl & 3.0 & 3.0 & & 3.0 & All & 3.0 & 3.0 & & 3.0 & All \\
\hline 27 & ANlowout & 1.0 & 1.0 & 0.15 & & & 1.0 & 1.0 & 0.15 & & \\
\hline 28 & SNnophi & 3.0 & 3.0 & & 0.0 & & 3.0 & 3.0 & & 0.0 & \\
\hline 29 & $\mathrm{SNq}$ & 3.0 & 3.0 & 3.0 & 3.0 & & 3.0 & 3.0 & 3.0 & 3.0 & \\
\hline 30 & SNqnophi & 3.0 & 3.0 & 3.0 & 0.0 & & 3.0 & 3.0 & 3.0 & 0.0 & \\
\hline 31 & SNloq & 3.0 & 3.0 & 0.45 & 3.0 & & 3.0 & 3.0 & 0.45 & 3.0 & \\
\hline 32 & SNloqnophi & 3.0 & 3.0 & 0.45 & 0.0 & & 3.0 & 3.0 & 0.45 & 0.0 & \\
\hline 33 & SNqpbl & 3.0 & 3.0 & 3.0 & 3.0 & All & 3.0 & 3.0 & 3.0 & 3.0 & All \\
\hline 34 & SNloqpbl & 3.0 & 3.0 & 0.45 & 3.0 & All & 3.0 & 3.0 & 0.45 & 3.0 & All \\
\hline 35 & ANhiq & 3.0 & 3.0 & 3.0 & & & 1.0 & 1.0 & 1.0 & & \\
\hline 36 & SNq_tropQ & 3.0 & 3.0 & 3.0 & 3.0 & Mid- $Q$ & 3.0 & 3.0 & 3.0 & 3.0 & Mid- $Q$ \\
\hline 37 & SNloq_tropQ & 3.0 & 3.0 & 0.45 & 3.0 & $\operatorname{Mid}-\widetilde{Q}$ & 3.0 & 3.0 & 0.45 & 3.0 & Mid- $\widetilde{Q}$ \\
\hline 38 & SNloq_tropQT & 3.0 & 3.0 & 0.45 & 3.0 & Mid- $Q, T$ & 3.0 & 3.0 & 0.45 & 3.0 & Mid- $Q, T$ \\
\hline 39 & SNloqt_tropQT & 3.0 & 0.45 & 0.45 & 3.0 & Mid- $Q, T$ & 3.0 & 0.45 & 0.45 & 3.0 & Mid- $Q, T$ \\
\hline 40 & SNloqt12h_tropQT & 3.0 & 0.225 & 0.225 & 3.0 & Mid- $Q, T$ & 3.0 & 0.225 & 0.225 & 3.0 & Mid- $Q, T$ \\
\hline 41 & SNlowerqt_tropQT & 3.0 & 0.1 & 0.1 & 3.0 & Mid- $Q, T$ & 3.0 & 0.1 & 0.1 & 3.0 & Mid- $Q, T$ \\
\hline 42 & AN6h & 1.0 & 1.0 & 0.15 & & & 0.45 & 0.45 & 0.1 & & \\
\hline
\end{tabular}

Some of the simulations are generally poor performers, regardless of the region, but they are not always the worst performers in Figs. 2-4. For example, simulation NN (no nudging) is among the least skillful in predicting temperature and precipitation when compared with the others, which all used some form of nudging in WRF. It is not surprising that a simulation without nudging is less skillful (cf. Lo et al. 2008; Bowden et al. 2012; Otte et al. 2012; Bullock et al. 2014; Omrani et al. 2015). Simulations with univariate nudging —in particular, toward only moisture 


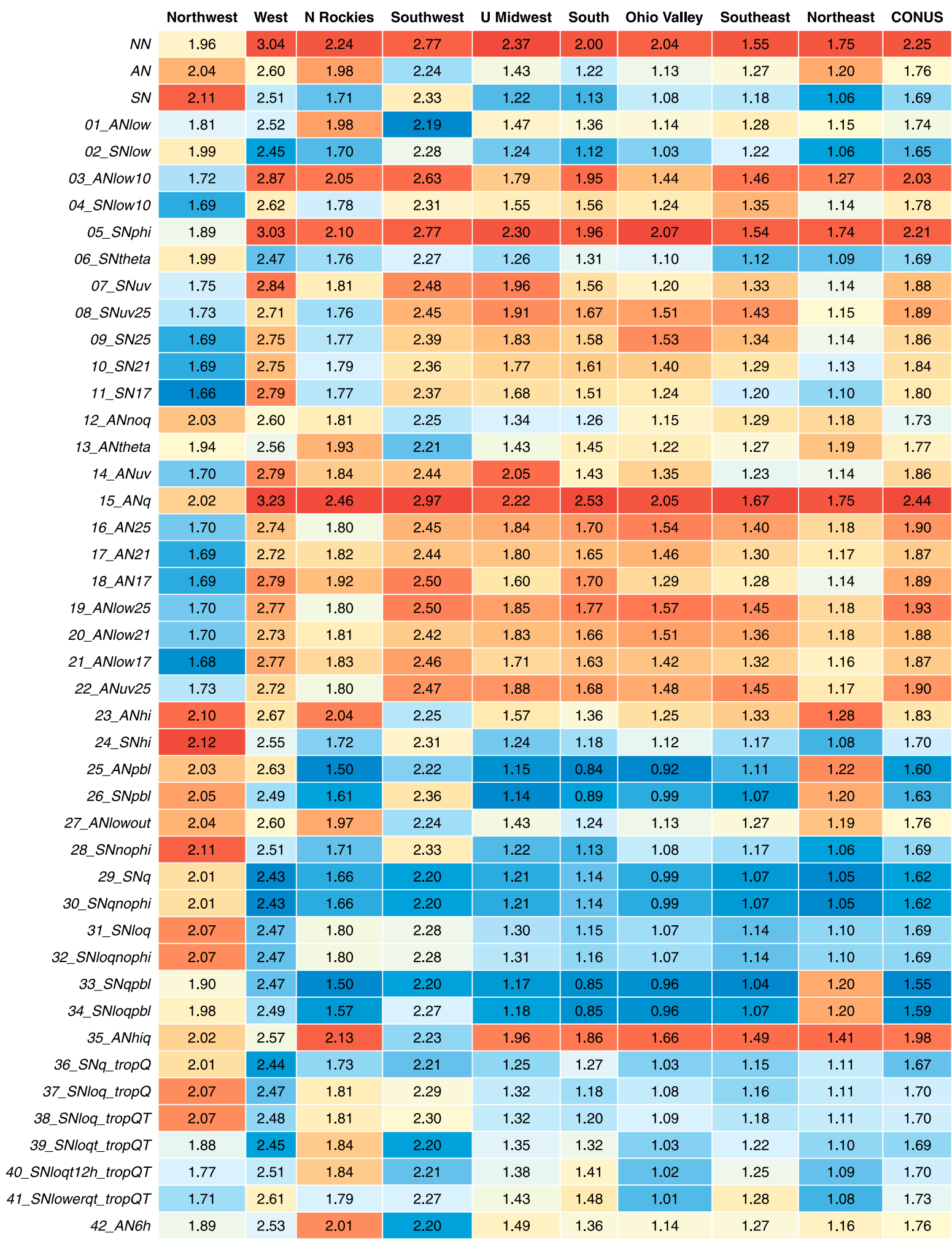

FIG. 2. Comparison of RMSE in mean 2-m temperature (K) for each WRF simulation (see Table 1) with CFSR and within the NCEI U.S. climate regions (Fig. 1) computed for 1988-90. Color shading indicates the ordinal rank of each WRF simulation within each region, where more-saturated blue indicates higher-ranked (lower error) simulations and more-saturated red indicates lower-ranked (higher error) simulations. 


\begin{tabular}{|c|c|c|c|c|c|c|c|c|c|c|}
\hline & Northwest & West & N Rockies & Southwest & U Midwest & South & Ohio Valley & Southeast & Northeast & CONUS \\
\hline$N N$ & 2.60 & 3.23 & 2.78 & 2.63 & 3.32 & 2.22 & 2.80 & 2.20 & 2.64 & 2.69 \\
\hline$A N$ & 2.62 & 3.23 & 1.88 & 2.62 & 1.66 & 1.39 & 1.42 & 1.56 & 1.45 & 2.05 \\
\hline$S N$ & 2.84 & 3.17 & 1.98 & 2.75 & 1.81 & 1.34 & 1.49 & 1.49 & 1.37 & 2.10 \\
\hline 01_ANlow & 2.50 & 3.03 & 1.88 & 2.46 & 1.73 & 1.47 & 1.50 & 1.69 & 1.42 & 2.01 \\
\hline 02_SNlow & 2.82 & 3.14 & 2.01 & 2.79 & 1.87 & 1.33 & 1.50 & 1.49 & 1.36 & 2.11 \\
\hline 03_ANlow10 & 2.32 & 3.02 & 2.08 & 2.28 & 2.29 & 2.04 & 2.05 & 2.12 & 1.73 & 2.22 \\
\hline 04_SNlow10 & 2.43 & 2.92 & 2.01 & 2.24 & 2.09 & 1.65 & 1.77 & 1.73 & 1.53 & 2.06 \\
\hline 05_SNphi & 2.46 & 3.19 & 2.52 & 2.59 & 3.13 & 2.15 & 2.84 & 2.20 & 2.57 & 2.60 \\
\hline 06_SNtheta & 2.92 & 3.19 & 2.24 & 2.80 & 1.91 & 1.50 & 1.64 & 1.50 & 1.33 & 2.20 \\
\hline O7_SNuv & 2.48 & 2.94 & 2.31 & 2.25 & 2.70 & 1.72 & 1.92 & 1.84 & 1.69 & 2.21 \\
\hline 08_SNuv25 & 2.55 & 3.01 & 2.35 & 2.36 & 2.87 & 2.18 & 2.44 & 2.13 & 1.83 & 2.41 \\
\hline 09_SN25 & 2.40 & 2.96 & 2.31 & 2.27 & 2.82 & 2.05 & 2.55 & 2.05 & 1.78 & 2.36 \\
\hline $10 \_S N 21$ & 2.38 & 2.92 & 2.30 & 2.29 & 2.71 & 1.90 & 2.27 & 1.85 & 1.76 & 2.27 \\
\hline 11_SN17 & 2.27 & 2.88 & 2.16 & 2.27 & 2.51 & 1.74 & 1.94 & 1.64 & 1.63 & 2.13 \\
\hline 12_ANnoq & 2.85 & 3.29 & 1.95 & 2.71 & 1.82 & 1.38 & 1.47 & 1.54 & 1.43 & 2.12 \\
\hline 13_ANtheta & 2.92 & 3.26 & 2.27 & 2.78 & 1.80 & 1.58 & 1.61 & 1.55 & 1.48 & 2.22 \\
\hline 14_ANuv & 2.43 & 2.93 & 2.43 & 2.25 & 3.08 & 2.12 & 2.40 & 1.93 & 1.78 & 2.38 \\
\hline 15_ANq & 2.45 & 3.29 & 2.52 & 2.55 & 2.68 & 2.51 & 2.51 & 2.05 & 2.39 & 2.56 \\
\hline 16_AN25 & 2.43 & 2.97 & 2.27 & 2.27 & 2.84 & 2.16 & 2.64 & 2.26 & 1.90 & 2.41 \\
\hline 17_AN21 & 2.31 & 2.92 & 2.12 & 2.21 & 2.75 & 2.08 & 2.50 & 2.03 & 1.87 & 2.30 \\
\hline 18_AN17 & 2.17 & 2.92 & 1.86 & 2.16 & 2.17 & 1.92 & 2.16 & 2.08 & 1.73 & 2.13 \\
\hline 19_ANlow25 & 2.46 & 2.99 & 2.26 & 2.28 & 2.79 & 2.23 & 2.59 & 2.30 & 1.86 & 2.41 \\
\hline 20_ANlow21 & 2.40 & 2.94 & 2.19 & 2.24 & 2.78 & 2.14 & 2.58 & 2.12 & 1.91 & 2.36 \\
\hline 21_ANlow17 & 2.28 & 2.93 & 2.02 & 2.19 & 2.55 & 2.06 & 2.42 & 2.12 & 1.84 & 2.26 \\
\hline 22_ANuv25 & 2.55 & 3.01 & 2.34 & 2.34 & 2.85 & 2.17 & 2.35 & 2.24 & 1.88 & 2.41 \\
\hline 23_ANhi & 2.58 & 3.28 & 1.93 & 2.55 & 1.82 & 1.41 & 1.54 & 1.57 & 1.55 & 2.07 \\
\hline 24_SNhi & 2.82 & 3.13 & 1.97 & 2.68 & 1.87 & 1.42 & 1.54 & 1.49 & 1.40 & 2.10 \\
\hline 25_ANpbl & 2.66 & 3.40 & 1.85 & 2.72 & 1.63 & 1.40 & 1.23 & 1.43 & 1.38 & 2.06 \\
\hline 26_SNpbl & 2.78 & 3.17 & 2.20 & 2.87 & 1.92 & 1.75 & 1.56 & 1.45 & 1.38 & 2.22 \\
\hline 27_ANlowout & 2.63 & 3.23 & 1.88 & 2.62 & 1.65 & 1.41 & 1.42 & 1.56 & 1.44 & 2.05 \\
\hline 28_SNnophi & 2.84 & 3.17 & 1.98 & 2.76 & 1.82 & 1.34 & 1.49 & 1.49 & 1.36 & 2.10 \\
\hline $29 \_S N q$ & 2.98 & 3.38 & 2.04 & 3.02 & 1.74 & 1.38 & 1.47 & 1.48 & 1.44 & 2.21 \\
\hline 30_SNqnophi & 2.97 & 3.38 & 2.04 & 3.02 & 1.74 & 1.38 & 1.46 & 1.48 & 1.44 & 2.21 \\
\hline 31_SNloq & 2.71 & 3.16 & 1.88 & 2.73 & 1.67 & 1.32 & 1.48 & 1.46 & 1.47 & 2.06 \\
\hline 32_SNloqnophi & 2.71 & 3.15 & 1.88 & 2.73 & 1.67 & 1.32 & 1.49 & 1.46 & 1.46 & 2.06 \\
\hline 33_SNqpbl & 2.78 & 3.32 & 2.31 & 3.05 & 1.82 & 1.81 & 1.52 & 1.45 & 1.42 & 2.29 \\
\hline 34_SNloqpbl & 2.70 & 3.20 & 2.16 & 2.94 & 1.82 & 1.72 & 1.48 & 1.42 & 1.46 & 2.20 \\
\hline 35_ANhiq & 2.55 & 3.13 & 2.02 & 2.51 & 2.37 & 1.79 & 2.27 & 1.76 & 1.83 & 2.25 \\
\hline 36_SNq_tropQ & 2.81 & 3.21 & 1.97 & 2.83 & 1.68 & 1.45 & 1.50 & 1.52 & 1.49 & 2.13 \\
\hline 37_SNloq_tropQ & 2.68 & 3.12 & 1.88 & 2.69 & 1.69 & 1.33 & 1.50 & 1.48 & 1.49 & 2.05 \\
\hline 38_SNloq_tropQT & 2.69 & 3.12 & 1.89 & 2.72 & 1.69 & 1.35 & 1.52 & 1.50 & 1.50 & 2.06 \\
\hline 39_SNloqt_tropQT & 2.55 & 3.00 & 1.85 & 2.59 & 1.57 & 1.38 & 1.44 & 1.54 & 1.43 & 1.99 \\
\hline 40_SNloqt12h_tropQT & 2.42 & 2.91 & 1.82 & 2.41 & 1.58 & 1.40 & 1.39 & 1.59 & 1.41 & 1.93 \\
\hline 41_SNlowerqt_tropQT & 2.35 & 2.86 & 1.82 & 2.28 & 1.66 & 1.47 & 1.41 & 1.66 & 1.41 & 1.92 \\
\hline 42_AN6h & 2.54 & 3.09 & 1.89 & 2.53 & 1.66 & 1.42 & 1.43 & 1.63 & 1.42 & 2.01 \\
\hline
\end{tabular}

FIG. 3. As in Fig. 2, but for daily maximum 2-m temperature. 


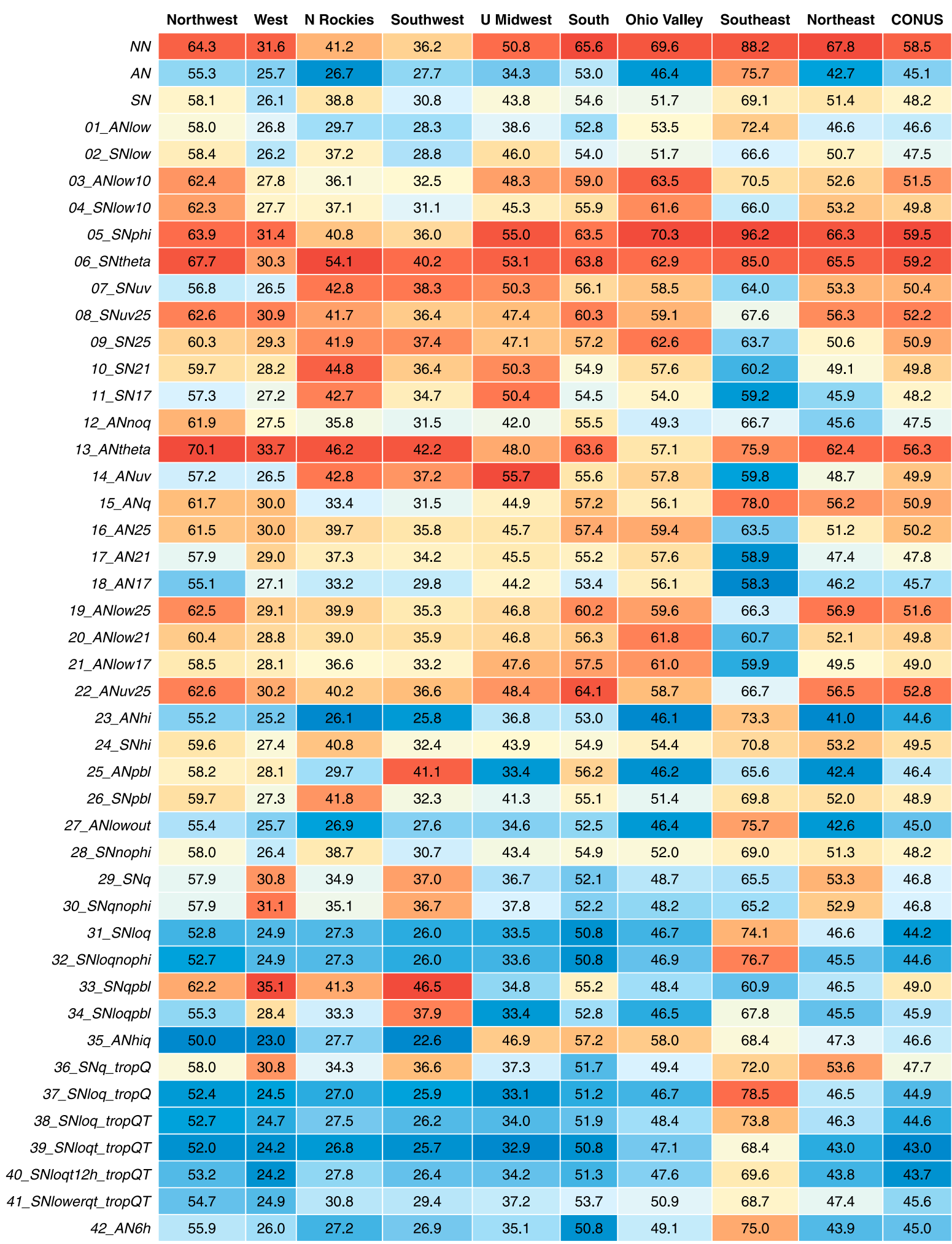

FIG. 4. As in Fig. 2, but for comparison of precipitation (mm) with CPC precipitation analyses. 
or geopotential (i.e., simulations 05 and 15) —can be as bad or worse than not using nudging at all, however. For example, the daily maximum 2-m temperature (Fig. 3) in simulation 15 (analysis nudging toward only moisture) has higher RMSE than NN in eight of the nine regions. Note that no published literature advocates the use of univariate nudging, and these simulations are provided only for didactic purposes. Ramamurthy and Carr (1988), Stauffer and Seaman (1990), and Stauffer et al. (1991) demonstrated that nudging multiple atmospheric fields simultaneously was consistently superior to univariate nudging.

A second theme from Figs. 2-4 is that, while there is some broad consistency in the ranked behavior of the WRF simulations, there is some regional variability, and the rankings for precipitation differ from those for temperature. For example, Fig. 2 shows that there is higher RMSE in mean 2-m temperature in the Northwest among simulations 23-38 (except 35), but those simulations have generally lower RMSE across the other eight regions. In daily maximum 2-m temperature (Fig. 3), the higher RMSE in simulations 23-38 extends also to the West and Southwest regions. Note that the range of the RMSE across the simulations in the Northwest (Figs. 2 and 3) and the West and Southwest (Fig. 3$)$ is smaller $(\sim 0.5 \mathrm{~K})$ than in the other regions. Also, the precipitation evaluation (Fig. 4) for many simulations between 23 and 38 shows that the RMSE is accentuated in the Southeast relative to the other eight regions; simulations 23-38 (except 35) use spectral nudging, which is less effective at mitigating error in the absence of strong synoptic forcing, such as during summertime in the Southeast.

This analysis suggests that there are other factors in the model physics and their interplay with nudging that can lead to different effects of these nudging strategies across the CONUS. For example, for 2-m temperature, it can be hypothesized that the regions closest to the western inflow boundaries tend to have better performance when nudging is used more sparingly, that is, with greater restrictions on the strength of the nudging (01-04, 19-22, and 39-42), the variables that are used (05-08, $12-15$, and 22), and where nudging is applied in the troposphere (08-11 and 16-22). In those locations, it is possible that the influence of the lateral boundary conditions is sufficient to constrain the simulation and that further constraint is detrimental. In addition, the predominance of complex terrain within those regions and its interplay with the nudging could also be a factor in degrading the regional performance. By contrast, simulations 29-34 and 36-41 use spectral nudging toward moisture, and that option (with the nudging coefficients used here) generally seems to improve precipitation throughout the CONUS, except during strongly active convective seasons (spring and summer) in the South, Southeast, and
Northeast regions (not shown). Exploring more closely the interactions of spectral nudging of moisture with the convective scheme warrants additional research, as does a greater focus on the nudging coefficient for moisture.

\section{c. Bivariate analysis}

For downscaling, it is important to assess the simulation of daily temperature extremes. Figure 5 is a bivariate "target plot" of the domain-averaged biases in daily maximum 2-m temperature and daily minimum 2-m temperature relative to CFSR for each of the seasons and throughout the simulation period. The annual bias uses the same data as in the last column of Fig. 3 but also illustrates persistent underpredictions and/or overpredictions. In Fig. 5, the simulations that are closer to the center have lower bias and greater skill for this bivariate metric.

In each season except winter, the simulations generally have a cold bias in daily maximum 2-m temperature and a warm bias in daily minimum 2-m temperature, indicating that this suite of physics options in WRF tends to suppress the diurnal range of 2-m temperature. In winter, most of the WRF simulations have either a cold or a warm bias common to both fields. The biases in both fields are collectively highest in the summer, as indicated by the fact that none of the simulations are within the innermost ring (bias within $\pm 0.5 \mathrm{~K}$ in both fields) and nearly one-half of the simulations have a combined bias that exceeds $\pm 1.5 \mathrm{~K}$. By contrast, about one-third of the simulations have a combined bias within $\pm 0.5 \mathrm{~K}$ in winter.

Simulations with univariate nudging that are generally less skillful across the regions in Figs. $2-4$ are confirmed to be less skillful throughout the seasons as well in Fig. 5 . In addition, simulation $\mathrm{NN}$ is never the least skillful simulation in any of the panels in Fig. 5. Thus, it is insufficient to simply state that nudging was used in the regional climate simulation to improve it; clearly, nudging can be used inappropriately and with detrimental effects. In addition, this analysis shows that simulations $24,31,32,36,37$, and notably 38 are among the least biased for these variables throughout the seasons and across the CONUS. All of these simulations except 24 use spectral nudging toward moisture.

Figure 6 is similar to Fig. 5 but compares the biases in annual mean 2-m temperature to total precipitation across the regions of the domain. These data illustrate the regional variations in the signs of the differences and not just the magnitudes of the data in Figs. 2 and 4. Many of the simulations shown in Figs. 5 and 6 represent improvements upon the base $\mathrm{AN}$ and $\mathrm{SN}$ configurations used in Otte et al. (2012) with nearly default coefficients. Figure 6 indicates that most of the simulations exhibit a wet bias throughout all regions of the CONUS, regardless of the type of nudging used. In the few simulations in 

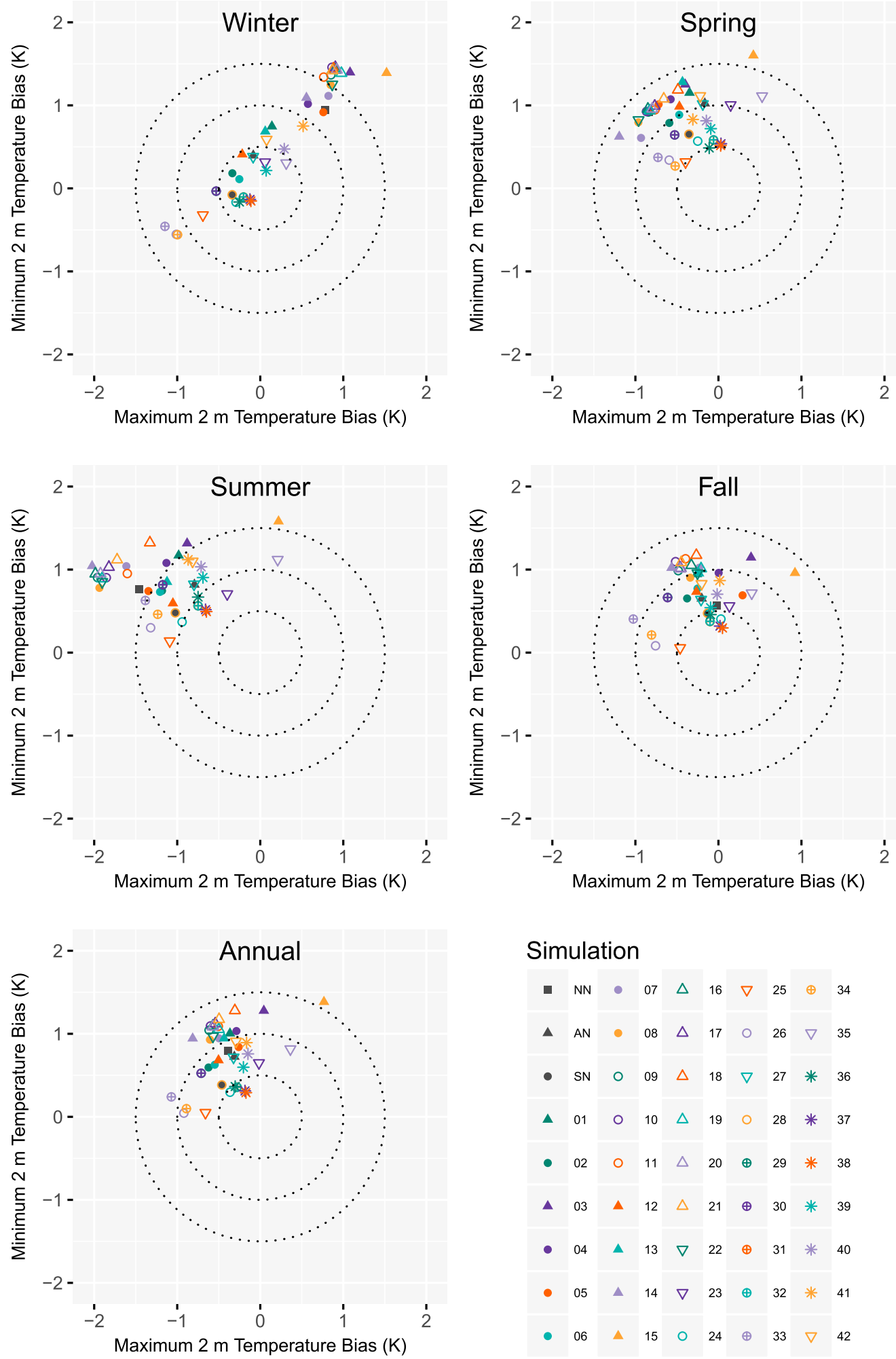

FIG. 5. CONUS-averaged bias in daily maximum 2-m temperature vs daily minimum 2-m temperature relative to CFSR for the WRF simulations during each boreal season and annually for 1988-90. Symbol shapes align with the nudging type used: squares indicate no nudging, triangles indicate analysis nudging, and circles indicate spectral nudging. Dotted rings are plotted at $0.5-\mathrm{K}$ intervals in each dimension. 

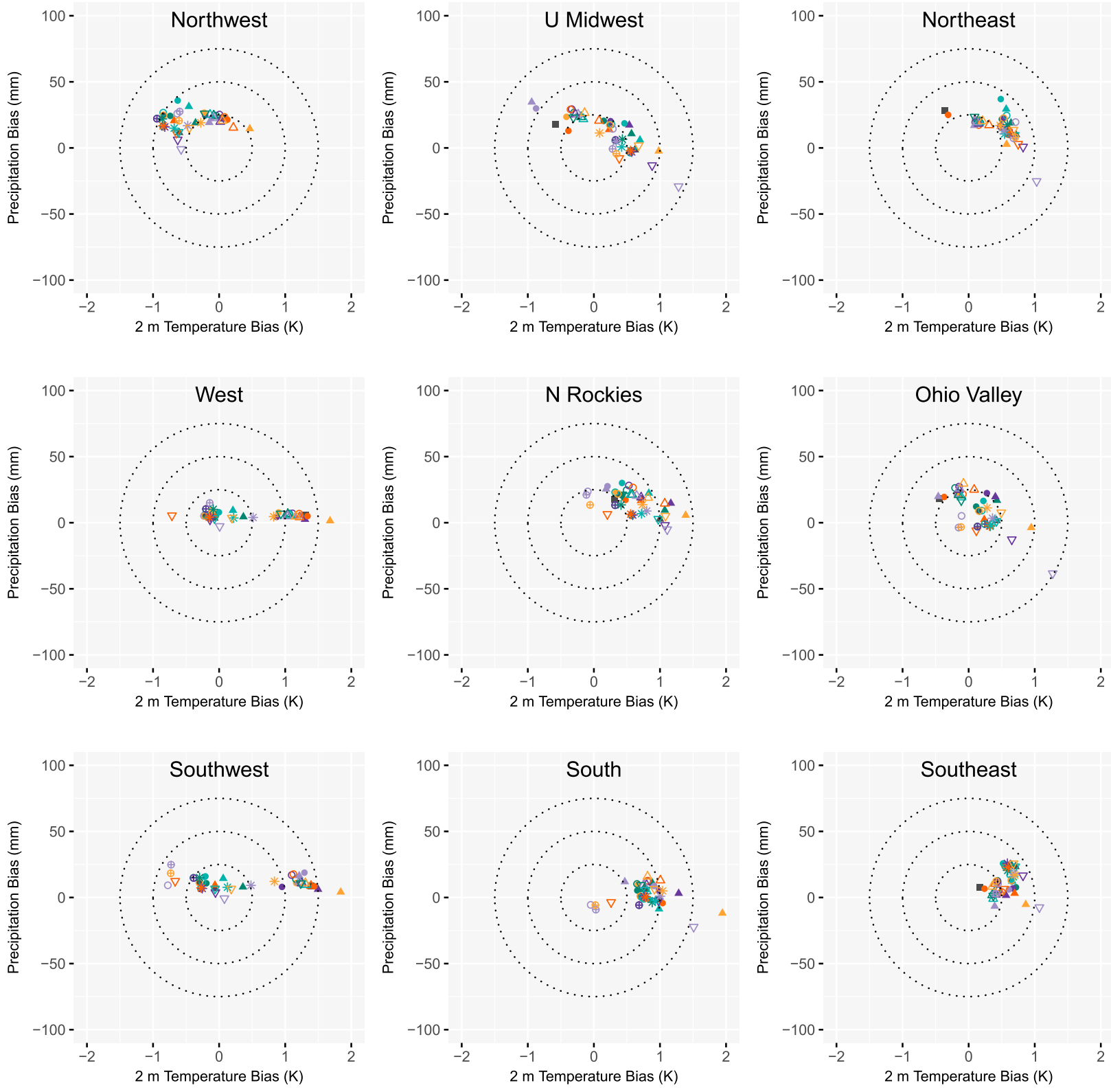

FIG. 6. Regionally averaged bias in annual mean 2-m temperature vs annual precipitation for each of the WRF simulations for $1988-90$. Dotted rings are at $0.5-\mathrm{K}$ and $25-\mathrm{mm}$ intervals. Color key is as in Fig. 5.

which there is a dry bias (analysis-nudging simulations 15,23 , and 35), the overcorrection is concurrent with larger degradations to the 2-m temperature than in the other simulations (Fig. 5); these simulations demonstrate the particular sensitivity of analysis nudging to the strength of the nudging coefficients. The simulations tend to have a warm bias in the eastern part of the CONUS and the Northern Rockies. There is a fairly even split of warm- and cool-biased runs in the West, Southwest, and Upper Midwest and mostly an overall cool bias in the Northwest. As with the large regional differences in the magnitudes of RMSE in Figs. 2-4, Fig. 6 shows that the WRF Model has a large regional variation in the quality of the simulation of 2-m temperature and precipitation. As in the seasonal analysis in Fig. 5, Fig. 6 shows that $\mathrm{NN}$ is never the simulation with the largest bivariate bias in any region.

\section{d. Extreme indices}

Figure 7 is a portrait diagram of extreme 2 -m temperature thresholds: summer days, frost days, tropical nights, and icing days. These indices examine WRF's 


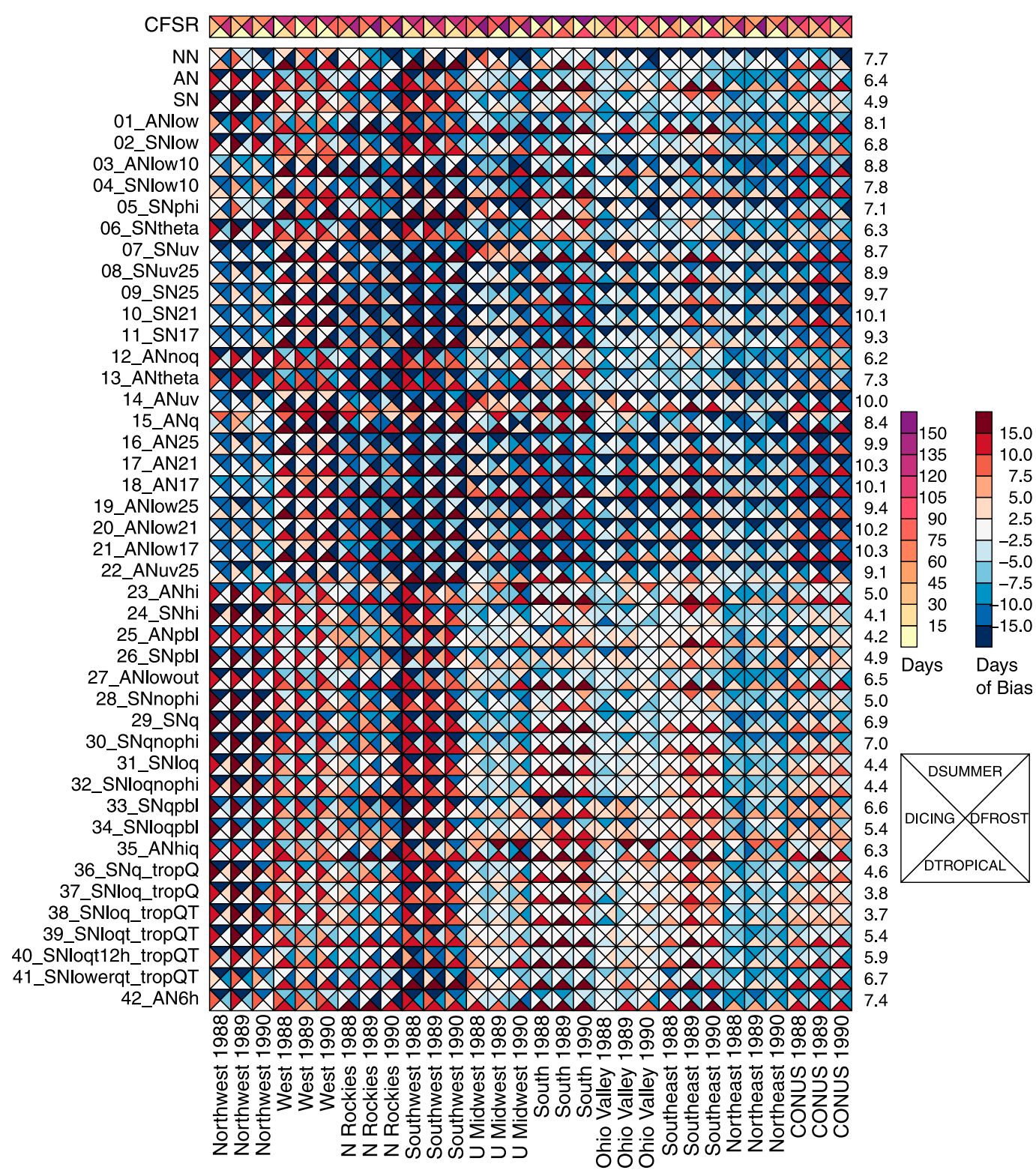

FIG. 7. Regionally averaged extreme 2-m temperature indices for 1988, 1989, and 1990. Values from CFSR are shown in the top row, and deviations from CFSR are shown in the remaining rows for each of the WRF simulations. Data in each square represent (clockwise from top) summer days (DSUMMER; $T_{\max }>25^{\circ} \mathrm{C}$ ), frost days (DFROST; $T_{\min }<0^{\circ} \mathrm{C}$ ), tropical nights $\left(T_{\min }>20^{\circ} \mathrm{C}\right.$ ), and icing days (DICING; $T_{\max }<0^{\circ} \mathrm{C}$ ). Numbers in the column to the right of the table are average errors across each index, in days per year.

ability to simulate extremes in daily maximum and daily minimum temperature on the warm end and the cold end of each spectrum. Interannual variations across the CONUS within this 3 -yr period are reflected in CFSR, as well as in how the WRF simulations deviate from CFSR. The less-saturated triangles in Fig. 7 have lower biases. At the right of the portrait diagram is a numerical score that aggregates the error in these indices across the regions, with lower values indicating greater skill.
Consistent with Figs. 2-6, Fig. 7 shows that several of simulations 23-42 have lower biases (greater skill) relative to the top half of the group of simulations in Table 1. Some of the least skillful simulations in Figs. 2-6 show some interannual variation in the biases in these indices across the regions (e.g., NN, 05, 06, 15, and 35), whereas there is little interannual variability in these metrics in CFSR. The simulations with the largest aggregate error restrict the nudging to above a layer in the 


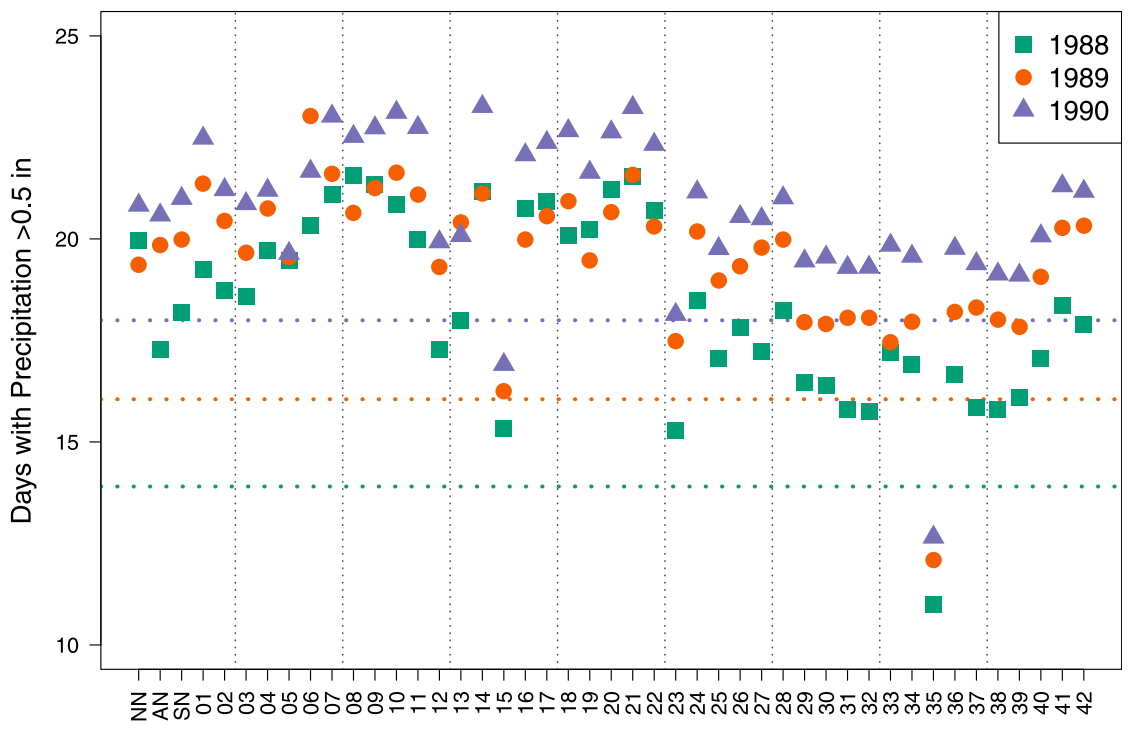

FIG. 8. CONUS-wide annual average number of days with precipitation greater than $0.5 \mathrm{in}$. (DP05) for 1988 (green), 1989 (orange), and 1990 (purple) for each of the WRF simulations. The dashed lines indicate the CONUS-wide average from CPC precipitation analyses.

midtroposphere (simulations $09-11$ and 16-21); the results are consistent regardless of whether analysis or spectral nudging was used. This implies that nudging should be used throughout the free troposphere to realize fully the benefits of nudging on the 2-m temperature fields. Simulations with spectral nudging toward moisture have the lowest collective biases for these indices, particularly simulations 37 and 38 (38 restricts the spectral nudging of both temperature and moisture to the free troposphere).

Figure 8 shows the average number of days with precipitation greater than 0.5 in. (DP05) at each grid cell across the CONUS. Each year is shown individually, as are the equivalent values from the CPC precipitation analysis. The high bias in DP05 across the domain and most simulations is consistent with Fig. 6. By considering only Fig. 8, simulations 15 and 23 would appear to be better performers for DP05, and simulation 35 overcorrects the wet bias; the precipitation is improved at the expense of the 2-m temperature in those runs, however (Figs. 2-7). There is negligible interannual variability in DP05 in simulation 05, and it is suppressed in simulations NN, 04, 09, 15, and 35. The order of wettest-todriest DP05 among the simulation years is incorrect in NN, 06, 08, 09, 14, 16, 17, and 19-22. The analysis from Figs. 2-8 suggests that none of the nudging strategies described in this paragraph should be used in WRF. Simulations that apply spectral nudging to moisture (29-39, except 35) reduce the wet bias while preserving skillful temperature results more effectively than most of the other nudging configurations.

\section{Themes among nudging strategies}

\section{a. Spectral nudging of geopotential}

Spectral nudging in WRF generally follows its implementation in RAMS (Miguez-Macho et al. 2004), where it is applied toward winds, modified equivalent potential temperature, and perturbation Exner function. Spectral nudging of the geopotential in WRF is intended to be analogous to nudging toward perturbation Exner function in RAMS.

Several pairs of sensitivity simulations demonstrate that there is minimal impact of spectral nudging toward geopotential in WRF (simulations $\mathrm{NN}$ and 05, SN and 28, 29 and 30, and 31 and 32). In comparing NN with 05 (spectral nudging toward only geopotential), there are very small differences in the regional RMSE in Figs. 2-4, as well as in the biases in Figs. 5 and 6. Those differences become negligible in the other three pairs of simulations in which spectral nudging toward wind, potential temperature, and sometimes moisture either added or excluded nudging toward geopotential. In those runs, the RMSE for temperature in Figs. 2 and 3 has negligible difference (usually less than $0.01 \mathrm{~K}$ ) across the regions and is very small (often less than $0.5 \mathrm{~mm}$ ) for precipitation. In addition, the biases for the runs in each pair are visually indistinguishable in Figs. 5 and 6 and are barely discernable in Figs. 7 and 8. These findings for a 3-yr period corroborate the results presented by Omrani et al. (2015), who used a "BigBrother Experiment" with 3-month European simulations in summer and winter. 


\section{b. Nudging in the column}

There has been no consensus on the extent of the atmospheric column that should be nudged in dynamical downscaling. Observation-driven nudging has generally not been performed in the PBL so that the local-scale features can be developed within the regional model (Stauffer and Seaman 1994). That approach was explored for downscaling in WRF by Lo et al. (2008), who concluded that 2-m temperature could be improved by extending the nudging through the PBL, but at the expense of the precipitation. As a result, most downscaling applications with WRF have restricted nudging to above the PBL. To investigate the effects of nudging on large-scale circulation, Miguez-Macho et al. (2005) showed the importance of nudging throughout the free troposphere; restricting nudging to the upper troposphere was insufficient to mitigate the errors in precipitation in RAMS. Conversely, Alexandru et al. (2009) used CRCM for a summer case and examined spectral nudging throughout the column, as well as above 850,700 , and $500 \mathrm{hPa}$. They found that modest nudging aloft reduced internal variability; nudging was applied only for winds, however, and there were issues related to the interplay of the nudging with convective activity. Scinocca et al. (2016) nudged horizontal wind components and temperature in the coupled Canadian global and regional climate modeling systems (CanESM2 and CanRCM4) at full strength at pressures less than $850 \mathrm{hPa}$ but tapered nudging closer to the ground to mitigate "chaotic divergence" that results from nonlinearity in limited-area regional models. Spero et al. (2014) alternatively found that capping nudging at the tropopause (while also restricting nudging below the PBL) improved the representation of radiation, clouds, and precipitation in WRF.

Several sets of simulations explore the effects of nudging through various parts of the atmospheric column, including through the PBL. In three clusters of sensitivity simulations that are based on $\mathrm{AN}, \mathrm{SN}$, and 01 (simulations 16-18, 09-11, and 19-21, respectively), nudging was restricted to above layer $17(\sim 800 \mathrm{hPa})$, layer $21(\sim 700 \mathrm{hPa})$, and layer $25(\sim 500 \mathrm{hPa})$. This approach most closely aligns with Alexandru et al. (2009) but also applies nudging toward potential temperature and either moisture (with analysis nudging) or geopotential (with spectral nudging). In addition, simulations 25 and 26 are like AN and SN but use nudging within the PBL. In these clusters of simulations, the RMSE for 2-m temperature and precipitation (Figs. 2-4) generally decreases as nudging is used through more of the column (including into the PBL), regardless of whether analysis or spectral nudging is used. The exceptions are for $2-\mathrm{m}$ temperature in the westernmost regions (from complex terrain and/or inflow conditions) and for precipitation in the Southeast (from interactions with convection). The 2-m temperature extremes also tend to be better predicted among this group of simulations as nudging is extended into the PBL, as shown with lower aggregate bias in Fig. 7.

Two simulation groups are used to further explore nudging only toward winds in WRF (as is done in CRCM): AN, 14, 16, and 22 and SN, 7, 9, and 8. These groups use either analysis or spectral nudging, and they illustrate the effects of restricting nudging to winds, restricting nudging above $500 \mathrm{hPa}$, and both. Each of the simulations reflects a marked degradation in skill relative to the base runs in AN and SN, as reflected in Figs. 2-8. The reduced skill with these restrictions on nudging is particularly evident in the extremes in Figs. 7 and 8. This suite of runs illustrates how the strategy from Alexandru et al. (2009) in CRCM is less successful in WRF.

\section{c. Spectral nudging toward moisture}

Analysis nudging toward moisture is an option in WRF that follows from the implementation in MM5. MiguezMacho et al. (2004) did not include spectral nudging toward moisture in their implementation in RAMS (and subsequently in WRF), reasoning that the spatial heterogeneity of the moisture fields is unlikely to be reflected in the reference data for downscaling. Spero et al. (2014) demonstrated that there are benefits to spectrally nudging moisture in WRF, however. Likewise, the spectral nudging in Radu et al. (2008) included specific humidity in the regional climate simulations.

Simulations 29-41 (except 35) show the effects of adding spectral nudging toward moisture. These simulations tend to have lower RMSE than most of the other simulations except for 2-m temperature in the Northwest, daily maximum 2-m temperature in the Southwest, and precipitation in the Southeast (Figs. 2-4). Several of the simulations that spectrally nudge moisture also have lower biases regardless of the season and region (Figs. 5 and 6), although there is variation among these runs and not all strategies using nudging toward moisture are equally beneficial, as discussed further, below. In addition, many of these simulations reduce the biases in the extremes across the CONUS (Fig. 7), and they tend to reduce the wet bias in the precipitation extremes (Fig. 8). Many of these simulations have comparable or lower RMSE than SN across the CONUS, especially for precipitation, demonstrating the utility of spectral nudging toward moisture (cf. Spero et al. 2014).

\section{d. Default coefficients for nudging moisture}

The default nudging coefficients in WRF are equal for all variables, regardless of whether WRF is used 

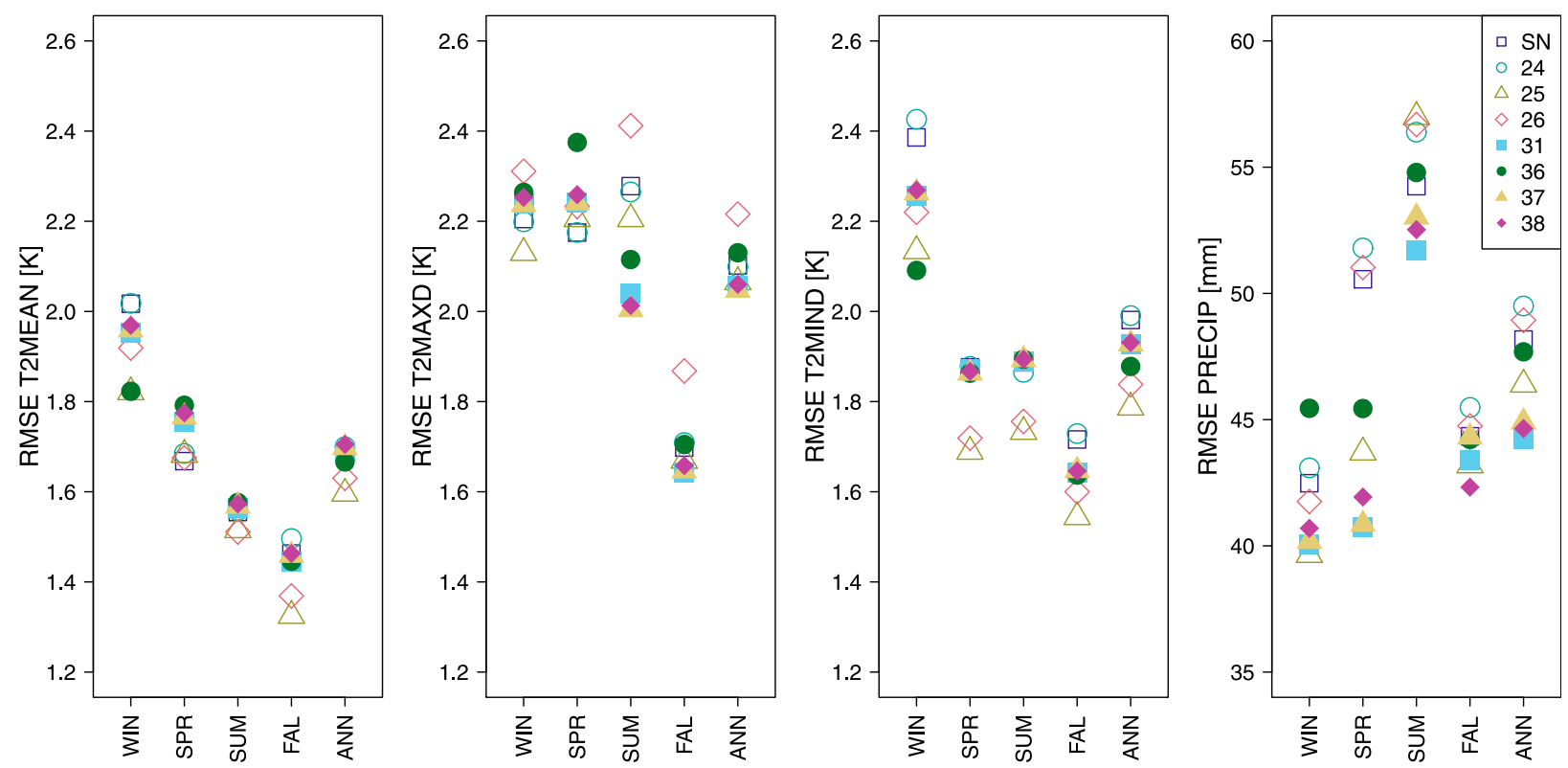

FIG. 9. CONUS-wide RMSE for (left) daily minimum 2-m temperature (K), (left center) daily mean 2-m temperature (K), (right center) daily maximum 2-m temperature $(\mathrm{K})$, and (right) precipitation $(\mathrm{mm})$ for each of the four boreal seasons, plus annually for selected WRF simulations. Two-meter temperatures are compared with CFSR, and precipitation is compared with CPC precipitation analyses. Data represent averages from 1988, 1989, and 1990.

for observation-based nudging or to constrain a regional climate simulation. The analysis-nudging coefficient for moisture in WRF is often reduced following Stauffer and Seaman (1994), but this change is sometimes overlooked because the benefits of adjusting the nudging coefficient for moisture in WRF have not been systematically studied.

Analysis-nudging simulations AN and 35 illustrate the deleterious effect of using the default nudging coefficient for moisture for regional climate modeling. Simulation 35 uses the default nudging coefficient for moisture on the outermost domain, and, although the nudging coefficients are reduced on the $36-\mathrm{km}$ domain (as is done for $\mathrm{AN}$ ), the nudging coefficient for moisture is applied at the same strength as for wind and temperature. As shown in section 3, simulation 35 is consistently among the least skillful simulations overall, particularly for temperature. Although simulation 35 appears to overcorrect the wet bias (Fig. 8), there is worsened skill for 2-m temperature, particularly in the eastern regions (Figs. 2, 3, and 6). Thus, the default analysis-nudging coefficient for moisture is too high to increase the skill of WRF when used as a regional climate model, and it should be reduced dramatically.

Reducing the nudging coefficient for moisture was also examined with spectral nudging in simulations 29 and 31,33 and 34 , and 36 and 37 . Reducing the nudging coefficient for moisture (as is done in simulations 31 , 32, 34, and 37) often increased RMSE for mean 2-m temperature (Fig. 2), but it tended to decrease the RMSE for daily maximum 2-m temperature (Fig. 3) and precipitation (Fig. 4). Reducing the nudging coefficient for moisture also improved simulations in each season (Fig. 5) and of the extremes (Figs. 7 and 8). Thus, if spectral nudging is used for moisture, the nudging coefficient should be reduced relative to that used for the other fields.

\section{e. Inference effect of nudging the parent domain onto the nested domain}

The inference effect of nudging from one domain to a nested domain is not understood well. Downscaling experiments by Salathé et al. (2008) used an NWPinspired strategy of only nudging the parent domain and not the inner nests, but Bowden et al. (2012) showed that nudging only the parent domain was insufficient to control the internal variability in the nested domain. Here, simulations AN and 27 demonstrate the sensitivity to nudging strength on the parent domain. There is a very small (often less than $0.01 \mathrm{~K}$ and $0.50 \mathrm{~mm}$ ) difference in the RMSE between AN and 27 (Figs. 2-4), with negligible differences in the bivariate seasonal analysis (Fig. 5) and extremes analysis (Figs. 7 and 8). Thus, similar to Bowden et al. (2012), the nested domain is strongly controlled by the strength of the 


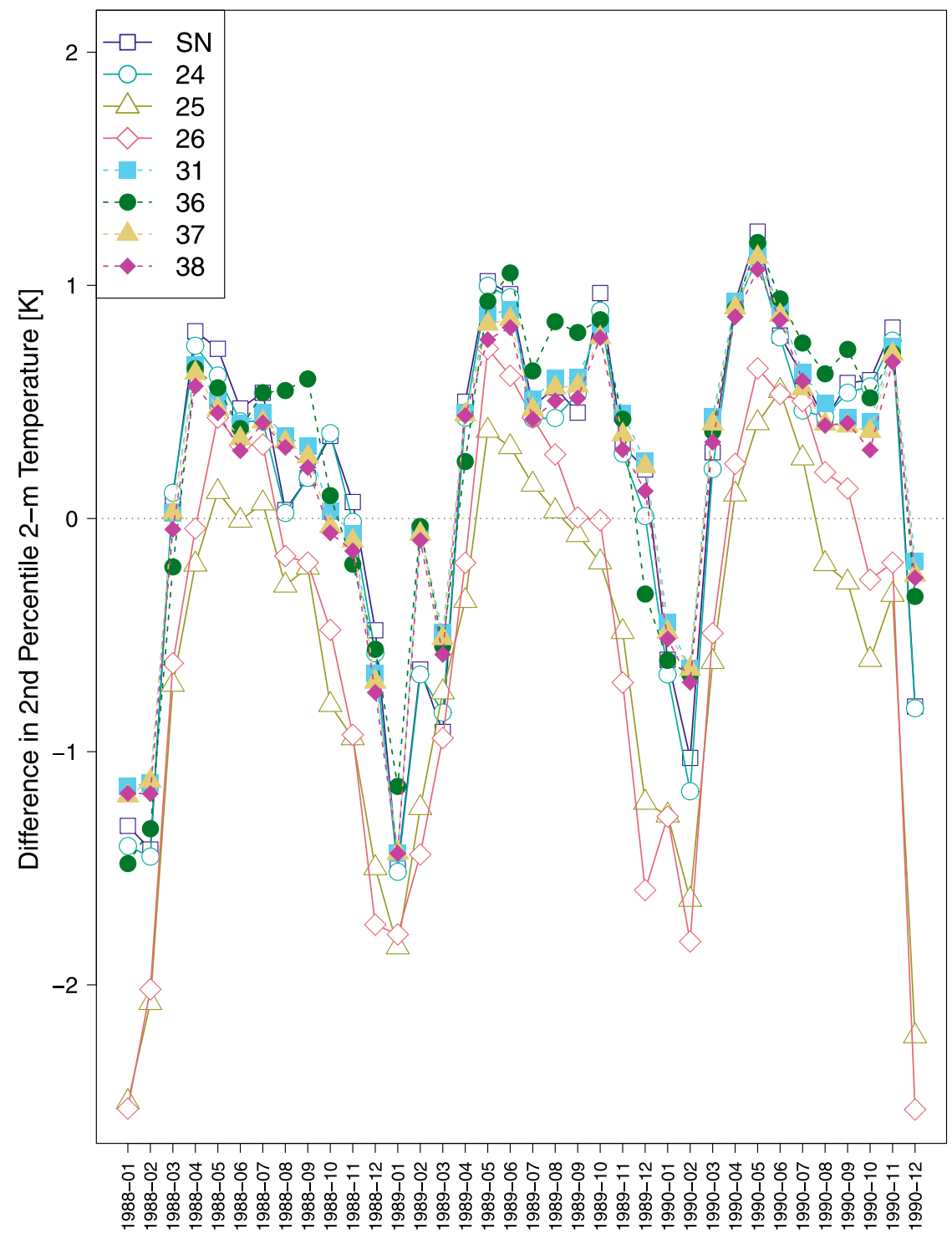

FIG. 10. Monthly difference in CONUS-wide second-percentile 2-m temperature (K) from selected WRF simulations compared with CFSR for 1988-90. The WRF simulations are described in Table 1.

nudging on that domain and is less influenced by the nudging strength on the parent domain.

\section{f. Nudging-strength "sweet spot"}

When nudging is used in WRF, there is a delicate balance between constraining the simulation toward the driving data and allowing WRF the freedom to develop scale-appropriate physics processes. In regional climate modeling, this is particularly important because there are no observations available to constrain WRF in future climate applications. Following Alexandru et al. (2009) and others, the prevailing theory is to nudge but only as weakly as possible.
Omrani et al. $(2012,2013)$ determined that a 6-h time scale was appropriate, but they acknowledged that the optimal time scale likely depends on the model configuration. Spero et al. (2014) also found that a 6-h time scale gave the best results, and they hypothesized that the optimal time scale is at the frequency of the driving data for downscaling. Several simulations explore the effects of reducing nudging strength on the resultant simulations.

Clusters of three simulations with analysis nudging (AN, 01, and 03) and spectral nudging (SN, 02, and 04) progressively reduce the nudging coefficients, and two simulations (23 and 24) increase the coefficients 


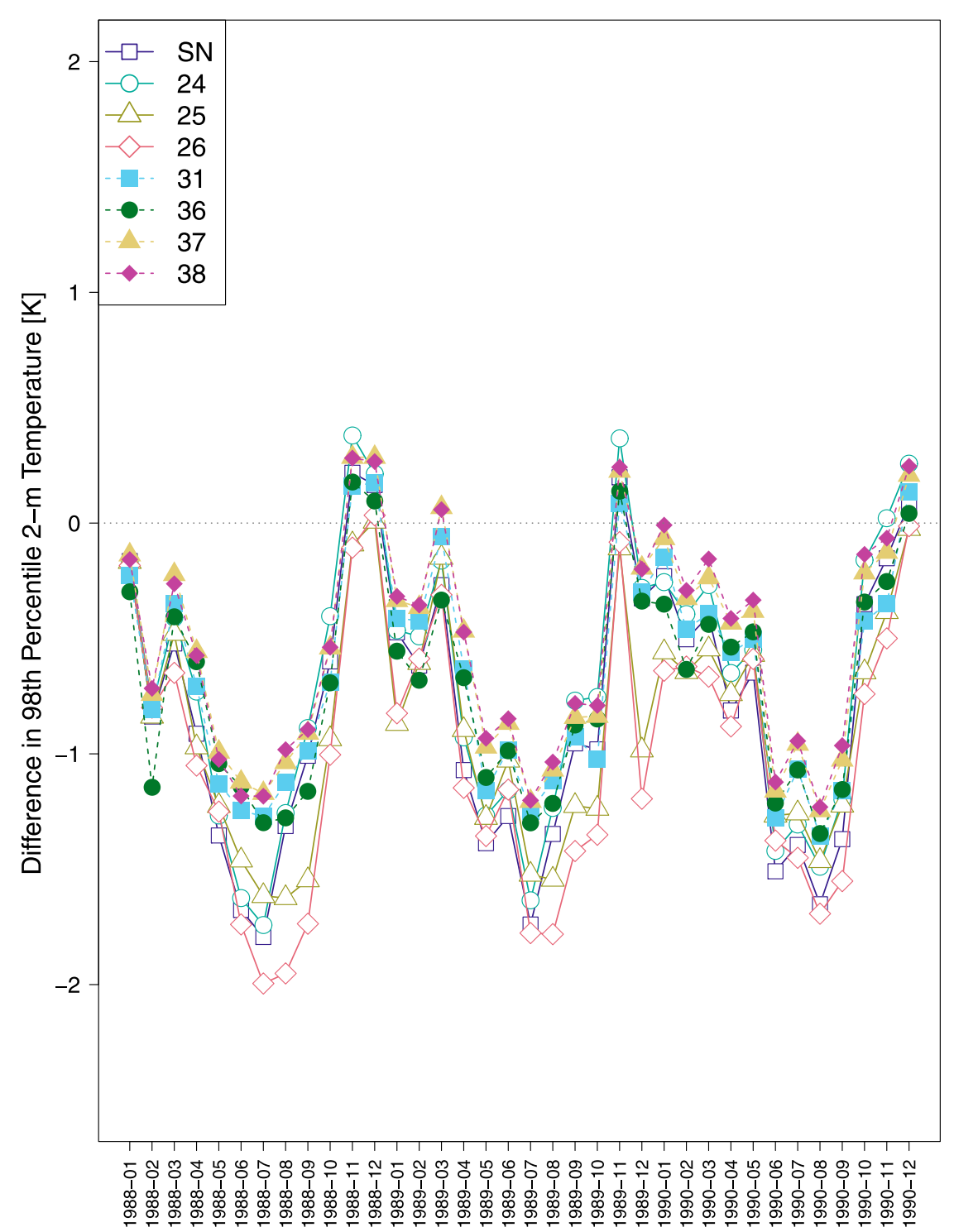

FIG. 11. As in Fig. 10, but for 98th-percentile 2-m temperature.

from the base values. Decreasing the analysis-nudging coefficients led to minor changes in simulation 01 but more dramatically reduced skill in simulation 03 (Figs. 2-4). There was no consistent impact across the regions by decreasing the spectral nudging coefficients in simulations 02 and 04 , although 02 is a net improvement in mean $2-\mathrm{m}$ temperature and precipitation and 04 was a net degradation. Thus, the nudging coefficients used in simulations 03 and 04 are too weak to be effective. Increasing the analysis-nudging coefficients in simulation 23 generally degraded the skill for 2-m temperature, and there was a minor effect from increasing the spectralnudging coefficients in simulation 24 . The decreased nudging coefficients worsened the extremes, whereas increased nudging coefficients improved them (Figs. 7 and 8).

A comparison of simulations 38 and 39 illustrates the effect of reducing the nudging coefficient for temperature, and both simulations have reduced strengths for moisture. Concurrently lowering the temperature coefficient leads to small improvements in the 2-m temperature and consistent improvements in precipitation (Figs. 2-4). Simulation 38 (with a higher coefficient for temperature relative to simulation 39) is a marked improvement over 39 in every season for maximum and minimum 2-m temperature (Fig. 5) and an improvement in the extremes (Figs. 7 and 8). This analysis suggests 


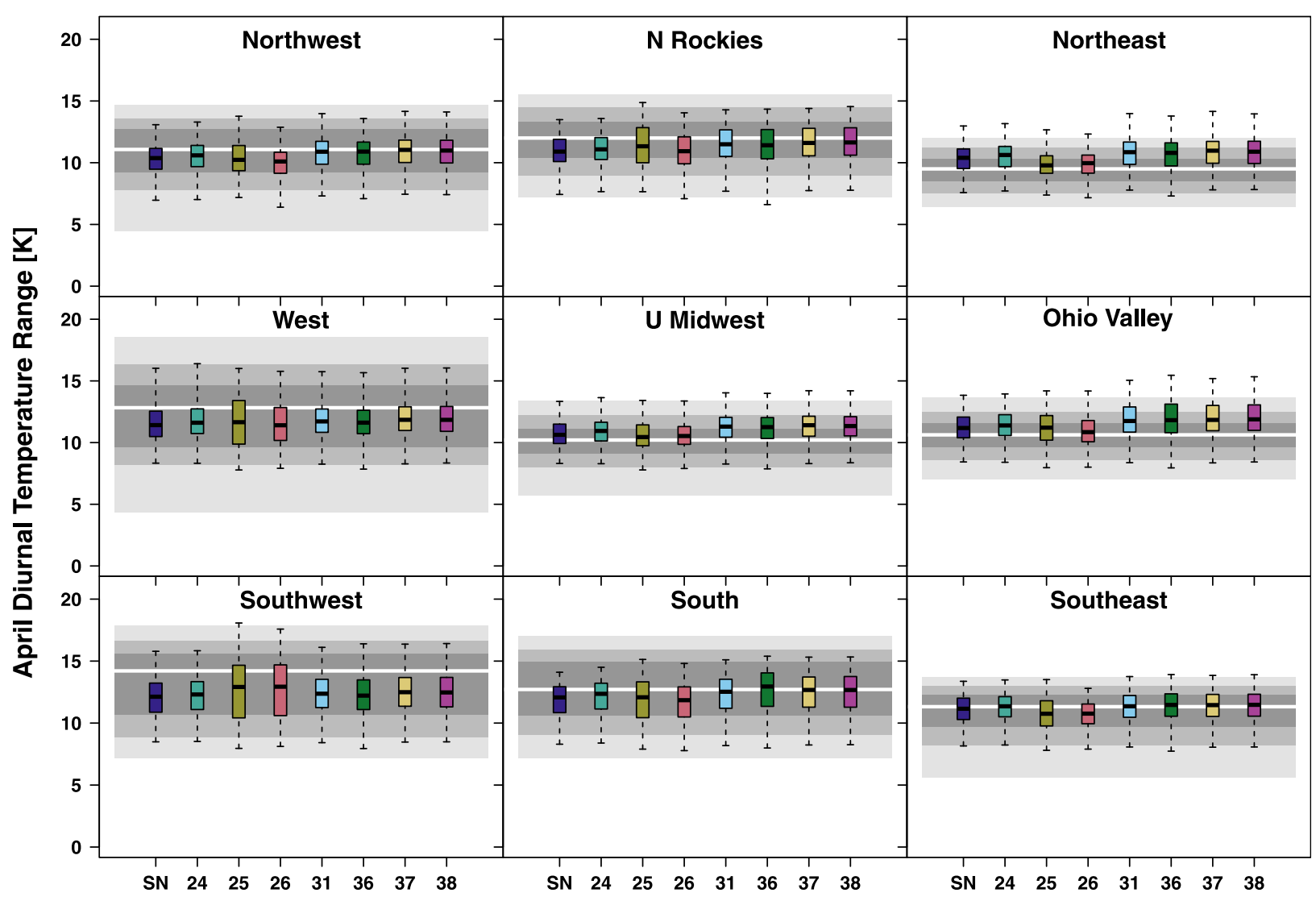

FIG. 12. Regional distribution of monthly diurnal temperature range (K) for selected WRF simulations for April 1988, April 1989, and April 1990. Boxplots indicate the median (solid black line), interquartile range (colored boxes), and data range between the second- and 98th-percentile values; outliers below the second percentile and above the 98th percentile are not shown. Gray shading represents the distribution of the regional values from CFSR, where the median is in white, the interquartile range is in the darkest shading, the range between the 10th and 90th percentiles is in slightly lighter shading, and the range between the second and 98th percentiles is in the lightest shading. Data are computed using monthly average values for April at each grid cell within each region for each of the three years. The monthly diurnal temperature range is computed as the difference between average daily maximum 2-m temperature and average daily minimum 2-m temperature at each grid point for each specific month.

that nudging the temperature as strongly as winds will have a positive impact on the extremes.

Simulations 39, 40, and 41 progressively reduce the coefficients for both temperature and moisture simultaneously. This configuration resulted in slight degradation of the mean 2-m temperature and precipitation with slight improvements in the daily maximum $2-\mathrm{m}$ temperature in every region (Figs. 2-4). The reduced coefficients also progressively lowered the skill in the simulated extremes (Figs. 7 and 8). These simulations are more skillful than $\mathrm{SN}$ for mean 2-m temperature and total precipitation but are less so for the extremes.

Simulation 42 uses analysis nudging with a 6-h time scale for nudging of winds and temperature, as recommended by both Omrani et al. (2013) at $50-\mathrm{km}$ grid spacing and Spero et al. (2014) at 36-km grid spacing. This simulation is comparable to simulation AN for mean 2-m temperature and precipitation (Figs. 2, 4, and 6), is better than $\mathrm{AN}$ in winter for daily maximum and minimum 2-m temperature but is worse in all other seasons (Fig. 5), and is worse than AN for the extremes (Figs. 7 and 8). Simulation 42 suggests that the 6-h time scale is not necessarily optimal for this configuration of WRF with analysis nudging.

\section{Analysis of most skillful configurations}

The eight most skillful simulations are analyzed to select an optimal nudging strategy for WRF to add value to regional climate projections in the midlatitudes. All of the simulations use spectral nudging except simulation 25. Those simulations include two in which nudging was performed throughout the atmospheric column and into the PBL (simulations 25 and 26), one with 


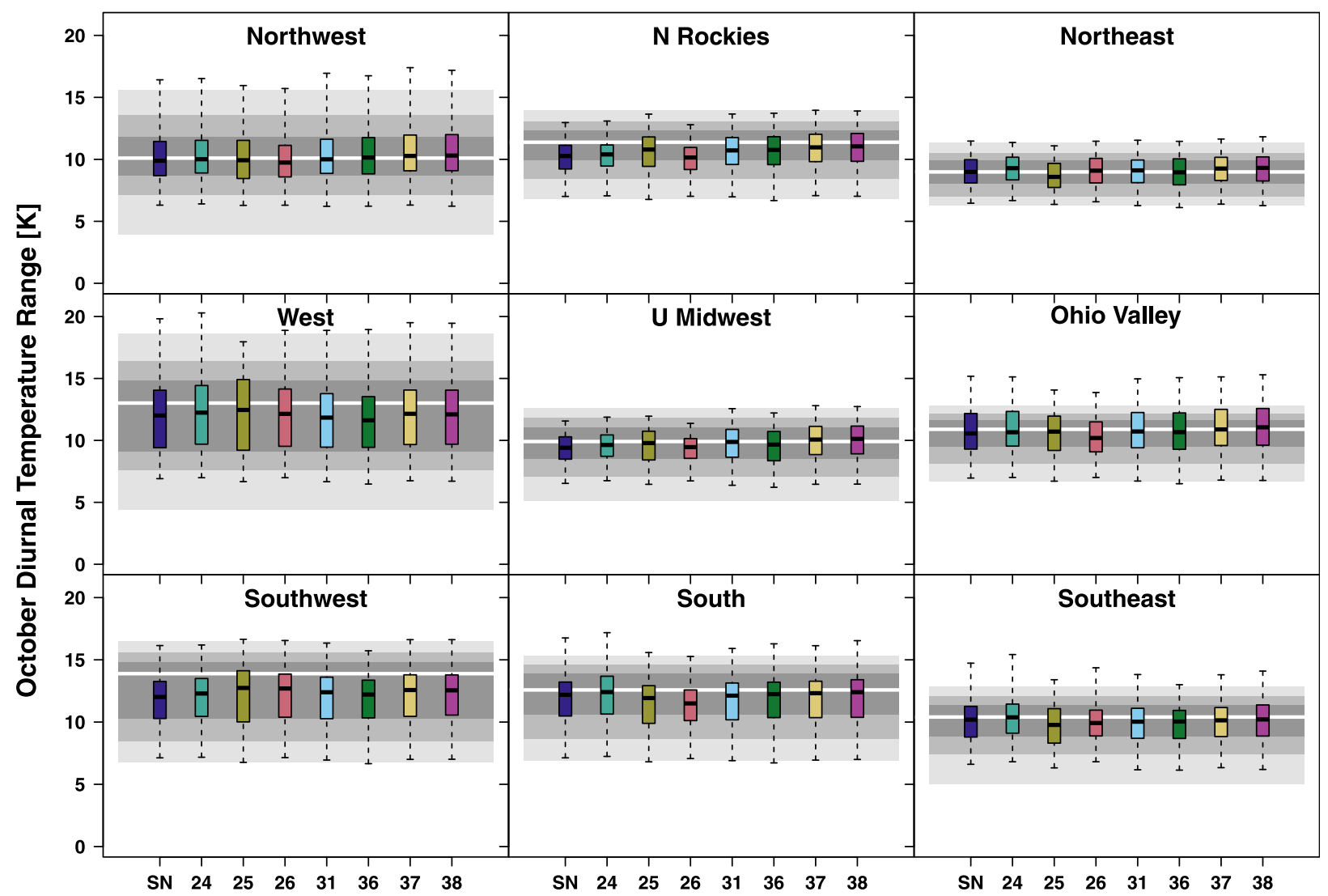

FIG. 13. As in Fig. 12, but for October.

increased nudging strength (simulation 24), and four with spectral nudging toward moisture (simulations 31 and 36-38), three of which also limit the nudging to below the tropopause. The base spectral-nudging simulation is included for reference.

The magnitudes of the RMSE for these simulations (Fig. 9) are typically much lower than those for the remaining simulations (see Figs. 2-4). Among this subset, the simulations that nudged in the PBL (simulations 25 and 26) often have the lowest RMSE by season for minimum daily $2-\mathrm{m}$ temperature and mean 2-m temperature but have the highest RMSE for precipitation. Simulations 31,37 , and 38 generally have lower RMSE than SN does, regardless of the variable or season.

The two simulations with nudging in the PBL (simulations 25 and 26) have much lower second- and 98th-percentile 2-m temperatures than the other simulations (Figs. 10 and 11), resulting in greater cold biases at these extremes despite the lower RMSE in the fields shown in Fig. 9. In particular, the differences in the secondpercentile temperatures for simulations 25 and 26 are more pronounced in the winter months, which would lead to worsened prediction of the winter extremes. Simulations 25 and 26 also have a more pronounced cold bias in the 98th-percentile temperature in the summer months and clearly demonstrate that nudging within the PBL causes performance to deteriorate for extreme temperatures relative to the other top-performing strategies. Although simulations 24 and 36 sometimes improve upon SN, they also tend to be inferior to simulations 31,37 , and 38 . Simulations 37 and 38 are often, but not always, the least biased simulations, with a slight advantage to simulation 38 , which is consistent with Figs. 7 and 8 and illustrates the important point that carefully applying spectral nudging to include moisture can improve simulated extreme temperatures.

Figures 12-15 examine diurnal temperature range and precipitation totals in the transition seasons. These figures examine the regional distributions of data in Fig. 5 and the seasonal distribution of data in Fig. 6. The bestperforming simulations generally underestimate the distribution of the diurnal 2-m temperature range within most regions in April (Fig. 12), which is consistent with Fig. 5. Simulation 25 tends to represent the magnitude of the interquartile range better than the other simulations. 


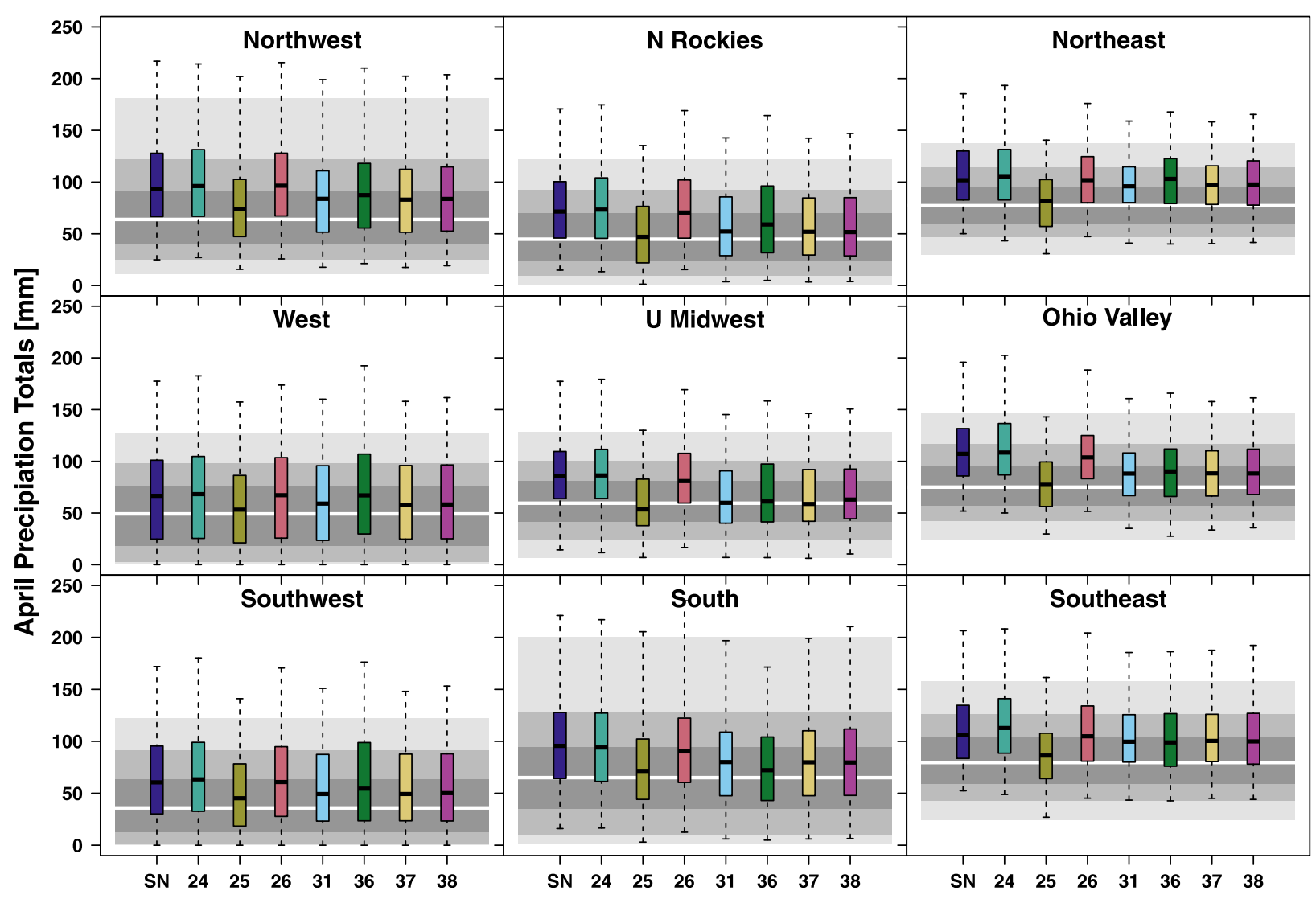

FIG. 14. As in Fig. 12, but for monthly precipitation (mm) compared with CPC precipitation analyses.

The medians are best represented by simulations 37 and 38 , which are less than $0.5 \mathrm{~K}$ from CFSR in four of the nine regions. The distribution of October diurnal range in the simulations (Fig. 13) is much better than that for April in many of the regions. All simulations produce a slight underestimation of the lower tail of the distribution in the Upper Midwest and overestimation of the upper tail in the Ohio Valley, but simulations 31, 37, and 38 provide improvements within the Southwest, Northern Rockies, South, and Northeast. In contrast with these runs, simulations $\mathrm{SN}$ and 24 often erroneously accentuate the width of the distribution (West, South, and Southeast) or suppress it (Southwest, Northern Rockies, and Upper Midwest).

The overprediction of precipitation across the simulations (Figs. 6 and 8) is evident in the distribution of April precipitation (Fig. 14). The precipitation is simulated well by simulation 25 (the only analysis-nudged simulation of this group), particularly in the Northern Rockies, South, Northeast, Ohio Valley, and Southeast. The simulations with spectral nudging toward moisture (simulations 31, 36,37 , and 38 ) correctly reduce the median precipitation totals relative to simulations $\mathrm{SN}, 24$, and 26 in most of the regions but have a greater tendency than simulation 25 to overpredict in some regions. By contrast, each of the simulations underpredicts the distribution of October precipitation (Fig. 15), except in the Southeast. The median in simulation 25 is systematically drier across the regions relative to the other simulations. The other differences between the simulations are subtle, although the Southeast (the region with the largest variability) is best simulated when spectral nudging of moisture is used (simulations 31, 36, 37, and 38).

The regionally averaged precipitable water for SN often is among the least skillful of the simulations in Fig. 16. Simulations SN, 24, and 26 (spectral nudging without moisture) are always clustered, with a positive bias in the Northwest and Northern Rockies and a negative bias elsewhere. Simulation 25 (with analysis nudging) produces error statistics that are more similar to the runs with spectral nudging of moisture simulations but is slightly worse in the South and Southeast. The four simulations with spectral nudging of moisture consistently have the best skill in Fig. 16, and they are generally indistinguishable, except for simulation 36 in the West and Southwest. 


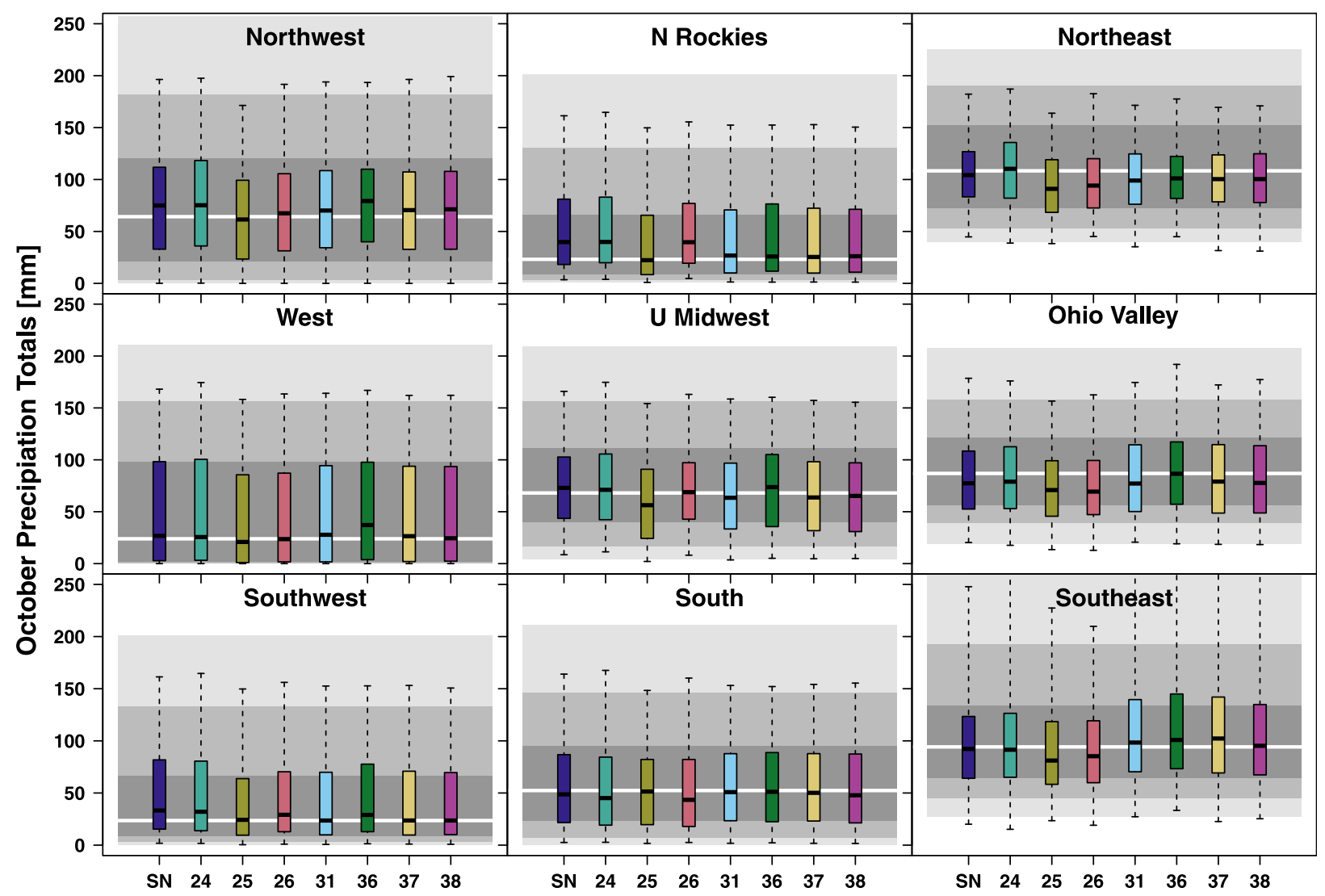

FIG. 15. As in Fig. 14, but for October.

\section{Conclusions}

Although the research presented here supports the use of nudging in regional climate simulations with WRF, nudging will not overcome all deficiencies in the model. For example, there is an obvious wet bias in this configuration of WRF. Some of the nudging strategies reduce but do not fully eliminate the wet bias, and others that seemingly alleviate the wet bias concurrently worsen the 2-m temperature simulations.

From this analysis, the following recommendations are given:

1) Use of either form of nudging, even without changes to the defaults, generally improves the skill of the regional climate simulation relative to not nudging at all.

2) The default nudging coefficient prior to version 4 of WRF $\left(3.0 \times 10^{-4} \mathrm{~s}^{-1}\right)$ is too strong to be used for either analysis or spectral nudging toward moisture.

3) Spectral nudging toward geopotential has a negligible effect when wind and temperature are also nudged.

4) Spectral nudging toward moisture improves the simulation of 2-m temperature and precipitation, and therefore it was added to the public release of WRF, version 4.
5) Nudging works best when it is used above the PBL. Omitting spectral nudging of temperature and moisture above the tropopause is also recommended; this suggestion has not been tested for analysis nudging.

6) Both analysis nudging and spectral nudging perform best when wind, temperature, and moisture are all nudged. Limiting the nudging to a subset of variables generally degrades model skill.

7) Use of improper nudging, such as univariate nudging, can worsen the simulation.

8) Determination of the optimal nudging coefficient requires additional research. The nudging coefficients should not be increased above the default values. Nudging too weakly renders it ineffective, however.

9) The simulation with the greatest skill overall (on the basis of this analysis) in this suite, simulation 38, applies spectral nudging toward wind, potential temperature, and moisture but uses a reduced nudging coefficient for moisture $\left(4.5 \times 10^{-5} \mathrm{~s}^{-1}\right)$. Here, nudging of winds is applied above the PBL (through the stratosphere), and it is restricted for both temperature and moisture to layers between the top of the PBL and the tropopause (i.e., to the free troposphere). 


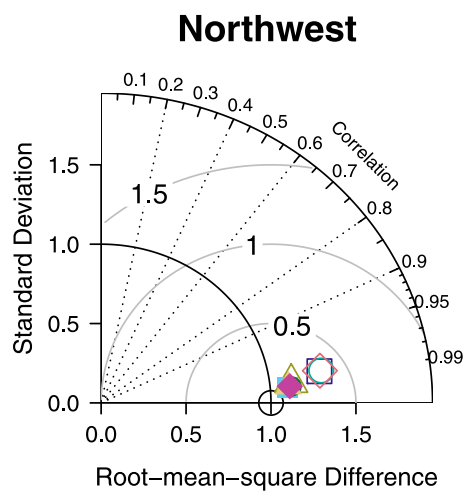

West

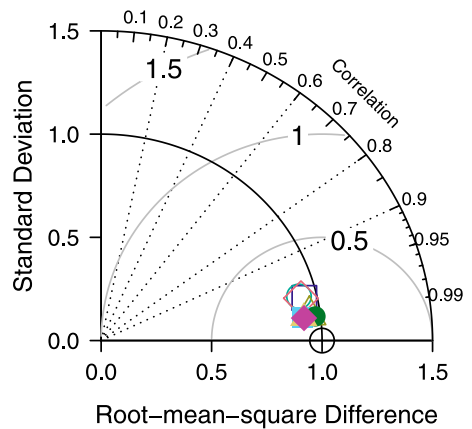

Southwest

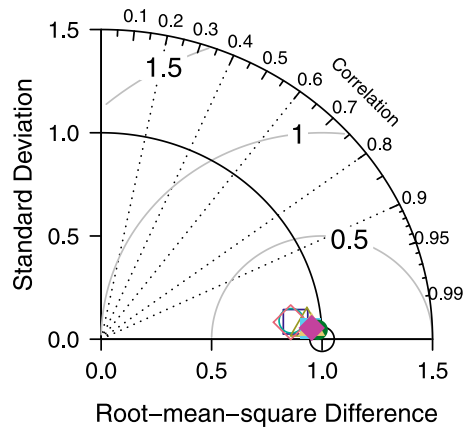

N Rockies

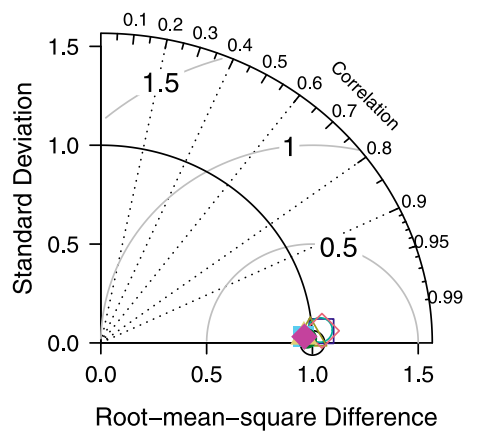

U Midwest

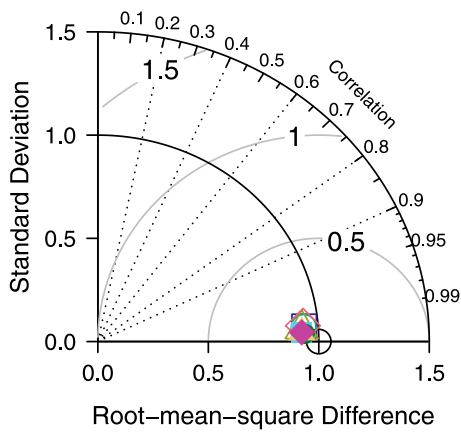

South

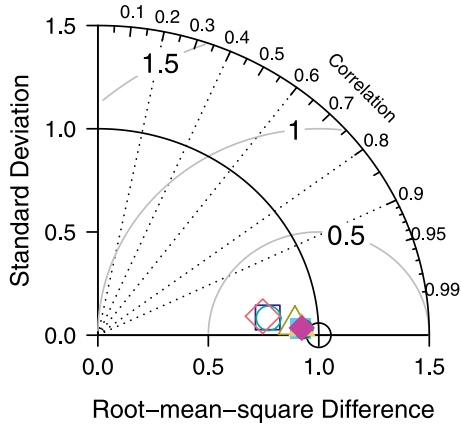

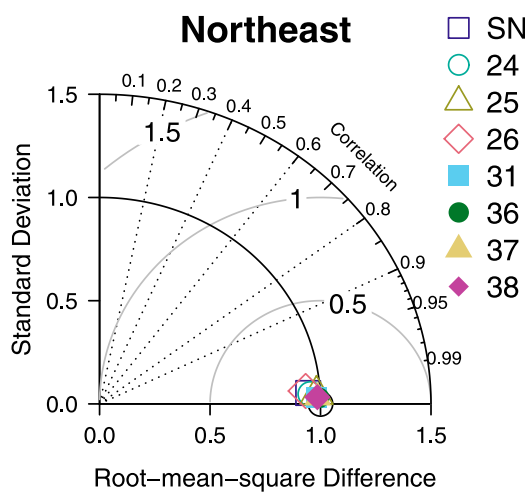

Ohio Valley

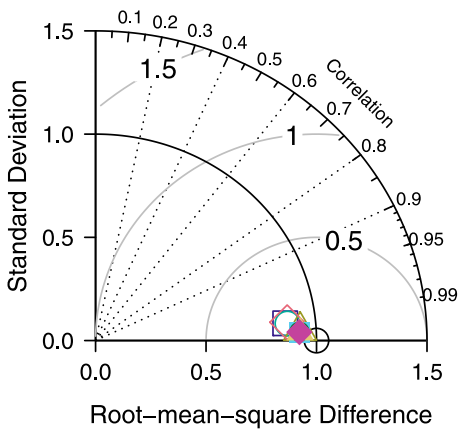

Southeast

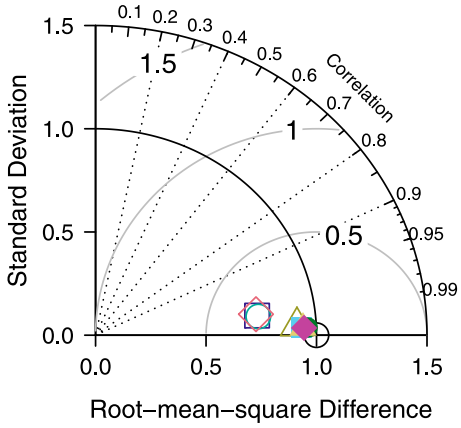

FIG. 16. Taylor diagrams of regionally averaged precipitable water from 1988 to 1990 for selected WRF sensitivity simulations compared with NARR. Statistics shown include normalized standard deviation (radially from origin), correlation coefficient (along azimuth), and centered root-mean-square difference (radially from reference of normalized standard deviation and correlation coefficient at 1).

Although these sensitivity simulations used version 3.2.1 of WRF (publicly released in 2010), substantially similar results have been achieved using a recent version of WRF (not shown). In the time that has elapsed, there were no major changes to the analysis-nudging and spectralnudging algorithms within WRF. In addition, improvements have been made to the physics options used here, and newer physics options have become available. Although only one configuration of WRF was used for the comprehensive study, preliminary results using 1-yr simulations performed on a larger 36-km domain with version 3.9 of WRF, different driving data (ERA-Interim), and a different suite of physics options have largely confirmed that the results shown here are robust. The research here focused only on nudging in the WRF Model, but these results and conclusions may also be applicable to other models. This analysis did not include humidity, clouds, winds, and mesoscale patterns, but these fields and others 
should be examined to solidify the nudging strategy. Additional research is needed to identify an optimal nudging strategy for finer grid spacing. Also, the nudging coefficient for moisture should be further refined, and this need will be addressed in a follow-on paper.

Acknowledgments. The authors thank Lara Reynolds (CSRA) for assistance in creating several of the simulations shown here and Michael Dudek (CSRA) for conducting preliminary analysis. The WRF Model was obtained from NCAR (http://www.wrf-model.org). The R-2 data, the NARR data, and the CPC U.S. Unified Precipitation data were obtained from the NOAA/OAR/ESRL/Physical Sciences Division (http://www.esrl.noaa.gov/psd). The CFSR data were obtained from NCEI (http://www.ncei.noaa.gov). The graphics were prepared using R software (http://www. r-project.org) with colorblind-accessible palettes. Russ Bullock and Chris Weaver from the U.S. EPA provided valuable technical feedback that strengthened this paper. The views expressed in this paper are those of the authors and do not necessarily represent the views or policies of the EPA.

\section{REFERENCES}

Alexandru, A., R. de Elía, R. Laprise, L. Separovic, and S. Biner, 2009: Sensitivity study of regional climate model simulations to large-scale nudging parameters. Mon. Wea. Rev., 137, 16661686, https://doi.org/10.1175/2008MWR2620.1.

Anthes, R. A., 1974: Data assimilation and initialization of hurricane prediction models. J. Atmos. Sci., 31, 702-719, https:// doi.org/10.1175/1520-0469(1974)031<0702:DAAIOH>2.0.CO;2.

Arnbjerg-Nielsen, K., P. Williams, J. Olsson, S. Beecham, A. Pathirana, I. Bülow Gregersen, H. Madsen, and V.-T.-V. Nguyen, 2013: Impacts of climate change on rainfall extremes and urban drainage systems: A review. Water Sci. Technol., 68 , 16-28, https://doi.org/10.2166/wst.2013.251.

Bowden, J. H., T. L. Otte, C. G. Nolte, and M. J. Otte, 2012: Examining interior grid nudging techniques using two-way nesting in the WRF Model for regional climate modeling. J. Climate, 25, 2805-2823, https://doi.org/10.1175/JCLI-D-11-00167.1.

- C. G. Nolte, and T. L. Otte, 2013: Simulating the impact of the large-scale circulation on the 2-m temperature and precipitation climatology. Climate Dyn., 40, 1903-1920, https:// doi.org/10.1007/s00382-012-1440-y.

Bullock, O. R., Jr., K. Alapaty, J. A. Herwehe, M. S. Mallard, T. L. Otte, R. C. Gilliam, and C. G. Nolte, 2014: An observation-based investigation of nudging in WRF for downscaling surface climate information to $12-\mathrm{km}$ grid spacing. J. Appl. Meteor. Climatol., 53, 20-33, https://doi.org/ 10.1175/JAMC-D-13-030.1.

Chai, T., and R. R. Draxler, 2014: Root mean square error (RMSE) or mean absolute error (MAE)? Arguments against avoiding RMSE in the literature. Geosci. Model Dev., 7, 1247-1250, https://doi.org/10.5194/gmd-7-1247-2014.

Chen, F., and J. Dudhia, 2001: Coupling and advanced land surface-hydrology model with the Penn State-NCAR MM5 modeling system. Part I: Model implementation and sensitivity. Mon. Wea. Rev., 129, 569-585, https://doi.org/10.1175/ 1520-0493(2001)129<0569:CAALSH >2.0.CO;2.
Deng, A., D. R. Stauffer, J. Dudhia, T. L. Otte, and G. K. Hunter, 2007: Update on analysis nudging FDDA in WRF-ARW. Proc. Eighth WRF Users' Workshop, Boulder, CO, National Center for Atmospheric Research, 4.8, http://www2.mmm.ucar.edu/ wrf/users/workshops/WS2007/abstracts/4-8_Deng.pdf.

Denis, B., R. Laprise, D. Caya, and J. Côté, 2002: Downscaling ability of one-way nested regional climate models: The BigBrother Experiment. Climate Dyn., 18, 627-646, https://doi.org/ 10.1007/s00382-001-0201-0.

Dickinson, R. E., R. M. Errico, F. Giorgi, and G. T. Bates, 1989: A regional climate model for the western United States. Climatic Change, 15, 383-422, https://doi.org/10.1007/BF00240465.

Fann, N., C. G. Nolte, P. Dolwick, T. L. Spero, A. Curry Brown, S. Phillips, and S. Anenberg, 2015: The geographic distribution and economic value of climate change-related ozone health impacts in the United States in 2030. J. Air Waste Manage. Assoc., 65, 570-580, https://doi.org/10.1080/10962247.2014.996270.

Feser, F., B. Rockel, H. von Storch, J. Winterfeldt, and M. Zahn, 2011: Regional climate models add value to global model data. Bull. Amer. Meteor. Soc., 92, 1181-1192, https://doi.org/ 10.1175/2011BAMS3061.1.

Flato, G., and Coauthors, 2013: Evaluation of climate models. Climate Change 2013: The Physical Science Basis, T. F. Stocker et al., Eds., Cambridge University Press, 741-866.

Giorgi, F., 1990: Simulation of regional climate using a limited area model nested in a general circulation model. J. Climate, 3, 941-963, https:// doi.org/10.1175/1520-0442(1990)003<0941:SORCUA > 2.0.CO;2.

Glisan, J. M., W. J. Gutowski Jr., J. J. Cassano, and M. E. Higgins, 2013: Effects of spectral nudging in WRF on Arctic temperature and precipitation simulations. J. Climate, 26, 3985-3999, https://doi.org/10.1175/JCLI-D-12-00318.1.

Gonzalez-Abraham, R., and Coauthors, 2015: The effects of global change upon United States air quality. Atmos. Chem. Phys., 15, 12 645-12 655, https://doi.org/10.5194/acp-15-12645-2015.

Grell, G. A., and D. Dévényi, 2002: A generalized approach to parameterizing convection combining ensemble and data assimilation techniques. Geophys. Res. Lett., 29, 1693, https:// doi.org/10.1029/2002GL015311.

Hoke, J. E., and R. A. Anthes, 1976: The initialization of numerical models by a dynamic-initialization technique. Mon. Wea. Rev., 104, 1551-1556, https://doi.org/10.1175/1520-0493(1976)104<1551: TIONMB $>2.0 . \mathrm{CO} ; 2$.

Hong, S.-Y., and J.-O. J. Lim, 2006: The WRF single-moment 6-class microphysics scheme (WSM6). J. Korean Meteor. Soc, 42, 129-151.

_- Y. Noh, and J. Dudhia, 2006: A new vertical diffusion package with an explicit treatment of entrainment processes. Mon. Wea. Rev., 134, 2318-2341, https://doi.org/10.1175/MWR3199.1.

Iacono, M. J., J. S. Delamere, E. J. Mlawer, M. W. Shephard, S. A. Clough, and W. D. Collins, 2008: Radiative forcing by longlived greenhouse gases: Calculations with the AER radiative transfer models. J. Geophys. Res., 113, D13103, https://doi.org/ 10.1029/2008JD009944.

Kanamitsu, M., W. Ebusuzaki, J. Woollen, S.-K. Yang, J. J. Hnilo, M. Fiorino, and G. L. Potter, 2002: NCEP-DOE AMIP-II Reanalysis (R-2). Bull. Amer. Meteor. Soc., 83, 1631-1643, https://doi.org/10.1175/BAMS-83-11-1631.

Karl, T. R., and W. J. Koss, 1984: Regional and national monthly, seasonal, and annual temperature weighted by area, 1895-1983. National Climatic Data Center Pub. Historical Climatology Series 4-3, 38 pp., https://repository.library.noaa.gov/view/noaa/10238.

Liu, P., A. P. Tsimpidi, Y. Hu, B. Stone, A. G. Russell, and A. Nenes, 2012: Differences between downscaling with spec- 
tral and grid nudging using WRF. Atmos. Chem. Phys., 12, 3601-3610, https://doi.org/10.5194/acp-12-3601-2012.

Lo, J. C.-F., Z.-L. Yang, and R. A. Pielke Sr., 2008: Assessment of three dynamical climate downscaling methods using the Weather Research and Forecasting (WRF) Model. J. Geophys. Res., 113, D09112, https://doi.org/10.1029/2007JD009216.

Mesinger, F., and Coauthors, 2006: North American Regional Reanalysis. Bull. Amer. Meteor. Soc., 87, 343-360, https://doi.org/ 10.1175/BAMS-87-3-343.

Miguez-Macho, G., G. L. Stenchikov, and A. Robock, 2004: Spectral nudging to eliminate the effects of domain position and geometry in regional climate model simulations. J. Geophys. Res., 109, D13104, https://doi.org/10.1029/2003JD004495.

- — North America: Interaction of local processes with improved large-scale flow. J. Climate, 18, 1227-1246, https://doi.org/ 10.1175/JCLI3369.1.

Nover, D. M., J. W. Witt, J. B. Butcher, T. E. Johnson, and C. P. Weaver, 2016: The effects of downscaling method on the variability of simulated watershed response to climate change in five U.S. basins. Earth Interact., 20, https://doi.org/10.1175/EI-D-15-0024.1.

Omrani, H., P. Drobinski, and T. Dubos, 2012: Spectral nudging in regional climate modelling: How strongly should we nudge? Quart. J. Roy. Meteor. Soc., 138, 1808-1813, https://doi.org/10.1002/qj.1894.

,-- , and,- 2013 : Optimal nudging strategies in regional climate modelling: Investigation in a Big-Brother Experiment over the European and Mediterranean regions. Climate Dyn., 41, 2451-2470, https://doi.org/10.1007/s00382-012-1615-6.

,-- , and -2015 : Using nudging to improve globalregional dynamic consistency in limited-area climate modeling: What should we nudge? Climate Dyn., 44, 1627-1644, https://doi.org/10.1007/s00382-014-2453-5.

Otte, T. L., 2008: The impact of nudging in the meteorological model for retrospective air quality simulations. Part I: Evaluation against national observation networks. J. Appl. Meteor. Climatol., 47, 1853-1867, https://doi.org/10.1175/2007JAMC1790.1.

_ C. G. Nolte, M. J. Otte, and J. H. Bowden, 2012: Does nudging squelch the extremes in regional climate modeling? J. Climate, 25, 7046-7066, https://doi.org/10.1175/JCLI-D-12-00048.1.

Pohl, B., and J. Crétat, 2013: On the use of nudging techniques for regional climate modeling: Application for tropical convection. Climate Dyn., 43, 1693-1714, https://doi.org/10.1007/ s00382-013-1994-3.

Radu, R., M. Déqué, and S. Somot, 2008: Spectral nudging in a spectral regional climate model. Tellus, 60A, 898-910, https:// doi.org/10.1111/j.1600-0870.2008.00341.x.

Ramamurthy, M. K., and F. H. Carr, 1988: Four-dimensional data assimilation in the monsoon region. Part II: Role of temperature and moisture data. Mon. Wea. Rev., 116, 1896-1913, https://doi.org/ 10.1175/1520-0493(1988)116<1896:FDDAIT>2.0.CO;2.

Saha, S., and Coauthors, 2010: The NCEP Climate Forecast System Reanalysis. Bull. Amer. Meteor. Soc., 91, 1015-1057, https:// doi.org/10.1175/2010BAMS3001.1.

Salathé, E. P., Jr., R. Steen, C. F. Mass, and P. H. Zahn, 2008: A highresolution climate model for the U.S. Pacific Northwest: Mesoscale feedbacks and local responses to climate change. J. Climate, 21, 5708-5726, https://doi.org/10.1175/2008JCLI2090.1.

Scinocca, J. F., and Coauthors, 2016: Coordinated global and regional climate modeling. J. Climate, 29, 17-35, https://doi.org/ 10.1175/JCLI-D-15-0161.1.

Seltzer, K. M., C. G. Nolte, T. L. Spero, K. W. Appel, and J. Xing, 2016: Evaluation of near surface ozone and particulate matter in simulations driven by dynamically downscaled historical meteorological fields. Atmos. Environ., 138, 42-54, https://doi. org/10.1016/j.atmosenv.2016.05.010.

Skamarock, W. C., and J. B. Klemp, 2008: A time-split nonhydrostatic atmospheric model for weather research and forecasting applications. J. Comput. Phys., 227, 3465-3485, https://doi.org/10.1016/j.jcp.2007.01.037.

Spero, T. L., M. J. Otte, J. H. Bowden, and C. G. Nolte, 2014: Improving the representation of clouds, radiation, and precipitation using spectral nudging in the Weather Research and Forecasting Model. J. Geophys. Res. Atmos., 119, 1168211 694, https://doi.org/10.1002/2014JD022173.

Stauffer, D. R., and N. L. Seaman, 1990: Use of fourdimensional data assimilation in a limited-area model. Part I: Experiments with synoptic-scale data. Mon. Wea. Rev., 118, 1250-1277, https://doi.org/10.1175/1520-0493(1990)118<1250: UOFDDA $>2.0 . \mathrm{CO} ; 2$.

— , and J.-W. Bao, 1993: Optimal determination of nudging coefficients using adjoint equations. Tellus, 45A, 358-369, https://doi.org/10.3402/tellusa.v45i5.14899.

— , and N. L. Seaman, 1994: Multiscale four-dimensional data assimilation. J. Appl. Meteor., 33, 416-434, https://doi.org/ 10.1175/1520-0450(1994)033<0416:MFDDA > 2.0.CO;2.

$\_,-$, and F. S. Binkowski, 1991: Use of four-dimensional data assimilation in a limited-area model. Part II: Effects of data assimilation within the planetary boundary layer. Mon. Wea. Rev., 119, 734-754, https://doi.org/10.1175/1520-0493(1991)119<0734: UOFDDA $>2.0 . \mathrm{CO} ; 2$.

,-- T. T. Warner, and A. M. Lario, 1993: Application of an atmospheric simulation model to diagnose air-pollution transport in the Grand Canyon region of Arizona. Chem. Eng. Commun., 121, 9-26, https://doi.org/10.1080/00986449308936135.

Tanrikulu, S., D. R. Stauffer, N. L. Seaman, and A. J. Ranzieri, 2000: A field-coherence technique for meteorological program design for air quality studies. Part II: Evaluation in the San Joaquin Valley. J. Appl. Meteor., 39, 317-334, https://doi.org/ 10.1175/1520-0450(2000)039<0317:AFCTFM>2.0.CO;2.

Trail, M., A. P. Tsimpidi, P. Liu, K. Tsigaridis, Y. Hu, A. Nenes, and A. G. Russell, 2013: Downscaling a global climate model to simulate climate change over the US and the implication on regional and urban air quality. Geosci. Model Dev., 6, 14291445, https://doi.org/10.5194/gmd-6-1429-2013.

von Storch, H., H. Langenberg, and F. Feser, 2000: A spectral nudging technique for dynamical downscaling purposes. Mon. Wea. Rev., 128, 3664-3673, https://doi.org/10.1175/ 1520-0493(2000)128<3664:ASNTFD>2.0.CO;2.

Waldron, K. M., J. Paegle, and J. D. Horel, 1996: Sensitivity of a spectrally filtered and nudged limited-area model to outer model options. Mon. Wea. Rev., 124, 529-547, https://doi.org/ 10.1175/1520-0493(1996)124<0529:SOASFA > 2.0.CO;2.

Wilson, A., B. J. Reich, C. G. Nolte, T. L. Spero, B. Hubbell, and A. G. Rappold, 2017: Climate change impacts on projections of excess mortality at 2030 using spatially varying ozonetemperature risk surfaces. J. Exposure Sci. Environ. Epidemiol., 27, 118-124, https://doi.org/10.1038/jes.2016.14.

Wootten, A., J. H. Bowden, R. Boyles, and A. Terando, 2016: The sensitivity of WRF downscaled precipitation in Puerto Rico to cumulus parameterization and interior grid nudging. J. Appl. Meteor. Climatol., 55, 2263-2281, https://doi.org/10.1175/ JAMC-D-16-0121.1.

Zou, X., I. M. Navon, and F. X. Ledimet, 1992: Optimal nudging data assimilation scheme using parameter estimation. Quart. J. Roy. Meteor. Soc., 118, 1163-1186, https://doi.org/10.1002/ qj. 49711850808 . 